\title{
CARACTERIZAÇÃO FUNCIONAL DA PROTEÍNA Coq10p DE Saccharomyces cerevisiae NA ATIVIDADE RESPIRATÓRIA DA COENZIMA $Q$
}

Tese apresentada ao Programa de PósGraduação em Microbiologia do Instituto de Ciências Biomédicas da Universidade de São Paulo, para obtenção do Título de Doutor em Ciências.

Área de Concentração: Microbiologia

Orientador: Prof. Dr. Mario Henrique de Barros

Co-orientador: Prof. Dr. José Ribamar Ferreira-Junior 


\section{RESUMO}

\section{BUSSO, C. Caracterização funcional da proteína Coq10p de Saccharomyces}

cerevisiae na atividade respiratória da coenzima Q. 2010. 100 f. Tese (Doutorado em Microbiologia) - Instituto de Ciências Biomédicas, Universidade de São Paulo, São Paulo, 2010.

A coenzima Q é uma molécula transportadora de elétrons das NADH e succinato desidrogenase para o complexo $b c 1$ da cadeia respiratória mitocondrial e possui dez genes envolvidos em sua biossíntese. O décimo gene: $C O Q 10$ foi descrito inicialmente também como necessário para a atividade respiratória da coenzima, porém, ao contrário dos demais mutantes, linhagens mutantes $\Delta$ coq10 apresentam concentrações normais de coenzima $\mathrm{Q}_{6}\left(\mathrm{CoQ}_{6}\right)$. A função exata de Coq10p ainda permanece obscura, sendo sugerida a sua participação na ligação e distribuição da CoQ. Neste intuito, diversos experimentos foram realizados na levedura $S$. cerevisiae com o objetivo de melhor compreender a função desta proteína. A utilização de inibidores da cadeia respiratória mitocondrial (antimicina A e mixotiazol) na linhagem $\Delta$ coq10, evidenciaram que a transferência de elétrons para o citocromo $b_{\mathrm{L}}$ ainda ocorre, com elevado índice de formação de $\mathrm{H}_{2} \mathrm{O}_{2}$ provavelmente de origem da semiquinona. A presença de semiquinona foi confirmada por ressonância paramagnética eletrônica (EPR) no mutante $\Delta$ coq10, indicando atividade do ciclo de regeneração de $\mathrm{CoQ}_{6}$. Quando superexpressa, a proteína Coq10p promove um declínio da atividade respiratória mitocondrial e elevada produção de $\mathrm{H}_{2} \mathrm{O}_{2}$, sugerindo uma interferência de Coq10p na distribuição da $\mathrm{CoQ}_{6}$. Para identificar possíveis regiões da proteína Coq10p que possam estar envolvidas na ligação da coenzima $\mathrm{Q}_{6}$, testes de mutagênese foram realizados nos resíduos de aminoácidos K50, L96, E105 e K162 no qual apresentam homologia à proteína CC1736 de Caulobacter crescentus e estão inferidos na ligação de compostos lipofílicos. As linhagens mutantes apresentaram deficiência respiratória e alto nível de produção de peróxidos, indicando a importância desses aminoácidos na associação com a coenzima $\mathrm{Q}_{6}$. Este trabalho contribui para melhor caracterizar esta importante proteína e confirma o seu papel central no metabolismo respiratório.

Palavras-chave: Saccharomyces cerevisiae. Coenzima $\mathrm{Q}_{6}$. Co10p. Estresse oxidativo, Cadeia respiratória mitocondrial. 


\begin{abstract}
BUSSO, C. Functional characterization of the Coq10p protein of Saccharomyces cerevisiae in coenzyme $\mathbf{Q}$ respiratory activity. 2010. 100 f. $\mathrm{Ph}$. D. Thesis (Microbiology) - Instituto de Ciências Biomédicas, Universidade de São Paulo, São Paulo, 2010.

Coenzyme $\mathrm{Q}$ is an electron carrier molecule of NADH and succinate dehydrogenase to the $b c 1$ complex of the mitochondrial respiratory chain and has ten genes involved in its biosynthesis. The tenth gene: $C O Q 10$ also was initially described as necessary for the respiratory activity of the coenzyme, however, unlike the other mutants, mutant strains $\Delta$ coq10 have normal concentrations of coenzyme $\mathrm{Q}_{6}\left(\mathrm{CoQ}_{6}\right)$. The exact function of Coq10p still remains unclear, and suggested its participation in binding and distribution of CoQ. To this end, several experiments were performed in the yeast $S$. cerevisiae in order to better understand the function of this protein. The use of inhibitors of mitochondrial respiratory chain (antimycin A and myxothiazol) $\Delta$ coqlo lineage, showed that the electron transfer to cytochrome $b_{\mathrm{L}}$ still occurs, with a high formation of $\mathrm{H}_{2} \mathrm{O}_{2}$ probably the source of the semiquinone. The presence of semiquinone was confirmed by electron paramagnetic resonance (EPR) in the mutant $\Delta$ coq 10 , indicating activity of the regeneration cycle of $\mathrm{CoQ}_{6}$. When overexpressed, the protein Coq10p promotes a decline in mitochondrial respiratory activity with a high production of $\mathrm{H}_{2} \mathrm{O}_{2}$, suggesting an interference in the distribution of Coq10p in $\mathrm{CoQ}_{6}$. To identify possible regions of the protein Coq10p that may be involved in the binding of coenzyme $\mathrm{Q}_{6}$, mutagenesis tests were performed in amino acid residues K50, L96, E105 and K162 in which homologous protein CC1736 of Caulobacter crescentus and are inferred in the binding of compounds lipophilic. The mutant strains were respiratory failure and high production of peroxides, indicating the importance of these amino acids in combination with coenzyme $\mathrm{Q}_{6}$. This work contributes to better characterize this important protein and confirms its central role in respiratory metabolism.
\end{abstract}

Keywords: Sacharomyces cerevisiae. Coenzyme Q6. Co10p. Oxidative stress. Mitochondrial respiratory chain. 


\section{INTRODUÇÃO}

\subsection{Saccharomyces cerevisiae como modelo de estudo mitocondrial}

Saccharomyces cerevisiae é o nome dado por Meyen, em 1837, ao fungo unicelular leveduriforme descoberto no malte empregado na produção de cerveja. Provavelmente é um dos organismos mais antigos domesticados pelo homem, sendo utilizado na Suméria e Babilônia há mais de 6.000 anos antes de Cristo. A palavra “enzimas" (en zymi = in levedura) originalmente foi dada por Kühne (1877) designando compostos derivados de levedura que são capazes de fermentar açúcar (FELDMANN, 2010).

Dentre as 700 espécies de leveduras conhecidas (em um reino de aproximadamente 700.000 diferentes fungos), S. cerevisiae destacou-se como modelo de estudo biológico a partir de experimentos de recombinação genética no loci adenina realizadas por Herschel Roman em 1956 (FELDMANN, 2010; ROMAN, $1956{ }^{1}$ apud GARTLER e STADLER, 1990). A partir destes estudos muitos pesquisadores subseqüentes perceberam que $S$. cerevisiae agregava uma excelente ferramenta para investigações da arquitetura e mecanismo celular. Dentre as principais vantagens no uso de S. cerevisiae como organismo-modelo pode-se citar: 1) é um organismo unicelular que (diferente de outros eucariotos mais complexos) pode crescer em um meio definido, o que favorece um completo controle sobre as interferências químicas e físicas do ambiente; 2) possui um ciclo de vida que é ideal para a genética clássica, o que possibilitou a construção de um mapa detalhado do conjunto haplóide de 16 cromossomos; 3) as células podem ser separadas da progênie por micromanipulação além de poder se manipulado geneticamente com facilidade; 4) pode ser mantido e estudado em estado haplóide e é um sistema bem conhecido de estudos de recombinação homóloga. (FELDMANN, 2010; GERSHON e GERSHON, 2000; GOFFEAU et al., 1996).

Além disso, a combinação de um grande número de cromossomos e um pequeno tamanho de genoma possibilitou o completo seqüenciamento genômico de $S$. cerevisiae

\footnotetext{
${ }^{1}$ ROMAN, H. Studies of gene mutation in Saccharomyces. Cold Spring Harbor Symp. Quant. Biol., v. 21, p. $175-185,1956$.
} 
em 1996 por Goffeau e colaboradores. Este evento permitiu ampliar novos estudos envolvendo esta levedura, principalmente no contexto evolucionáro. Com uma sequência de 12.068 kilobases, foi inferido que 5.885 genes codificam proteínas em potencial; aproximadamente 140 genes especificam o RNA ribossomal e outros 40 estão envolvidos em pequenos RNAs e finalmente, 275 genes codificam RNAs de transportadores (GOFFEAU et al., 1996).

A utilização de Saccharomyces cerevisiae como modelo de estudos mitocondriais tornou-se mais efetiva a partir sequenciamento de seu genoma nuclear o que possibilitou a descoberta de novos genes. Além disso, também é facilitado por ser um organismo aeróbio facultativo e com a possibilidade de isolar mutantes respiratórios em meios apropriados (FOURY e KUCEJ, 2001; GOFFEAU et al., 1996; OHLMEIER et al., 2004). A maioria dos genes que codificam proteínas mitocondriais são altamente conservados entre os eucariotos, servindo como um modelo para estudos fisiológicos de proteínas a nível mitocondrial (KRUFT et al., 2001; RABILLOUD et al., 1998). A partir de bancos genômicos de análise funcional, como o Saccharomyces Genome Database (SGD -29/06/2010), constata-se que cerca de 26\% do total de ORFs (Open Reading Frame - segmentos do genoma nuclear que contêm uma seqüência de bases potencialmente codificantes) ainda permanecem com funções desconhecidas.

Os primeiros estudos envolvendo a genética mitocondrial iniciaram-se no final da década de 1940 pelo francês Boris Ephrussi. A obtenção de linhagens mutantes de levedura com o emprego de acriflavina, um agente mutagênico, resultou na descoberta de uma mutação herdada citoplasmaticamente que promovia uma deficiência da função respiratória. Tal fato permitiu concluir que a morfogênese mitocondrial é controlada por um elemento genético não cromossomal que foi denominado fator $\rho$ ( $r h o$ ) (EPHRUSSI et al., 1949). Células $\rho^{0}$ são caracterizadas por apresentar ausência de DNA mitocondrial e são deficientes respiratórios em um meio com fonte de carbono não ferementável tipo etanol e glicerol (TZAGOLOFF e DIECKMANN, 1990). Somente na metade da década de 60 que a existência do DNA mitocondrial foi relatado pela primeira vez através de trabalhos realizados em leveduras por Schatz (1964).

Com a descoberta do DNA mitocondrial, novos estudos foram realizados no intuito de caracterizar este novo genoma. Neste sentido o genoma do DNA mitocondrial (mtDNA) de $S$. cerevisiae é conhecido por possuir 85.779 pares de base, que codificam 2 rRNAs, 24 tRNAs, 30 proteínas e 1/3 restante está envolvido em funções 
mitocondriais tais como a montagem de subunidades do complexo da ATP sintase, citocromo $b$ e complexo da citocromo $c$ oxidase (FOURY et al., 1998). Em contraste ao seu pequeno genoma, mais de 400 proteínas com funções conhecidas em levedura são codificadas no genoma nuclear e posteriormente importadas pela mitocôndria (HODGES et al., 1999).

O elevado grau de similaridade entre mitocôndrias de levedura e humanos tem possibilitado o uso de estudos genômicos funcionais de $S$. cerevisiae para identificar genes humanos nucleares envolvidos em doenças (BARRIENTOS, 2003), como foi o caso da identificação do gene DDPl envolvido em uma desordem auditiva (ROTHBAUER et al., 2001) e a mutação no gene COX associado a síndrome de Leigh (BARRIENTOS, 2003; NOBREGA et al., 1990). Atualmente há um consórcio internacional de laboratórios que empregam a deleção de todos os genes nucleares de $S$. cerevisiae com o objetivo de identificar proteínas mitocondriais. Este consórcio identificou mais de 250 genes em levedura com ortólogos em humanos e todos associados à deficiência de crescimento em substratos de fonte de carbono não fermentável (deficientes respiratórios) (STEINMETZ et al., 2002).

Doenças neurodegenerativas também estão associadas com disfunções mitocondriais, e novamente a utilização de S. cerevisiae como modelo de estudo possibilitou descobertas importantes na área médica. Um exemplo clássico foi a identificação do gene envolvido na ataxia de Friedreich, uma doença caracterizada por manifestações de ataxia cerebelar, neuropatia periférica, cardiopatia e diabetes (COOPER e SCHAPIRA, 2007). A inativação do gene localizado no cromossomo 9q13 humano e que codifica a proteína frataxina resulta na manifestação da doença. A proteína codificada por este gene não possui similaridade com proteínas de função conhecida o que dificultou sua identificação (CAMPUZANO et al., 1996; WALLACE, 2005). Pesquisas conduzidas a partir de vários estudos identificaram que YFH1, o homólogo da frataxina na levedura, é uma proteína envolvida no metabolismo do ferro (BABCOCK, 1997; FOURY e CAZZALINI, 1997; KOUTNIKOVA et al., 1997) e os dados obtidos em experimentos com levedura, demonstraram que pacientes com ataxia de Friedreich possuem uma deficiência em proteínas ferro-enxofre com acúmulo de ferro mitocondrial (na forma de radical), esta descoberta possibilitou desenvolver um tratamento terapêutico com a administração de ibedenona, um seqüestrador de radicais livres (LERMAN-SAGIE et al., 2001). 
O fato de que muitos genes envolvidos em desordens humanas estão associados com um grande espectro de fenótipos de deleção em levedura, e que podem ser identificados através da seleção do crescimento quantitativo deste microrganismo (BARRIENTOS, 2003), possibilitou o avanço no estudo de novas ORFs (genes em potencial). O particular interesse nas ORFs hipotéticas mitocondriais deve-se principalmente ao papel central da mitocôndria em doenças neurodegenerativas e no envelhecimento celular (JAZWINSKI, 2005; OHLMEIER et al., 2004; WALLACE, 1995).

\subsection{Mitocôndria: origem e função}

De acordo com a teoria endosimbionte proposta inicialmente por Lynn Margulis (1970), a origem da mitocôndria é resultado da simbiose entre uma $\alpha$-proteobactéria e uma arqueobactéria anaeróbica metanogênica. Este processo envolveu o intercâmbio de ATP produzido aerobicamente pelo simbionte por compostos orgânicos fornecidos pelo hospededeiro anaeróbico. Durante este processo muitos genes mitocondriais foram transferidos para o núcleo do hospedeiro, possivelmente como um resultado de seleção natural contrária aos efeitos danosos de radicais livres produzidos pela nova organela (ALLEN e RAVEN, 1996).

Evidências sobre o evento de transferência de genes mitocondriais para o núcleo da célula foram confirmadas in vitro em S. cerevisiae por Ricchetti et al. (1999), que identificaram seqüências curtas de origem mitocondrial no genoma nuclear desta levedura. Segundo estes autores a similaridade, tamanho e composição destas seqüências correspondem aos fragmentos oriundos da quebra de DNA envolvendo o sistema de reparo dupla-fita. Farrelly e Butow (1983), ao utilizarem uma porção do gene mitocondrial de levedura - varl, como sonda em estudos de homologia de sequências nucleares, encontraram regiões similares deste gene no DNA nuclear. Além disso, foram encontradas seqüências adjacentes correspondentes aos genes do citocromo $b$ (cob/box) e sequiências homólogas à porção ori/rep localizadas no DNA mitocondrial e envolvidas na replicação desta organela. Estes autores concluíram que estas sequências encontradas no núcleo, que se tornaram estáveis inegradas ao genoma nuclear de levedura, originaram-se de rearranjos de fragmentos de DNA, característicos de mutantes que perderam o DNA mitocondrial (petite). 
Sabe-se, portanto, que durante a evolução a maioria dos genes que eram transcritos no genoma mitocondrial foram transferidos para o núcleo, substituídos por genes nucleares preexistentes ou perdidos simultaneamente (ADAMS e PALMER, 2003; ANDERSSON et al., 2002). Esse processo ainda é contínuo e confirmado através de experimentos alotópicos como o demonstrado por Supekova et al. (2010) em $S$. cerevisiae. O gene mitocondrial COX2 (montagem da citocromo $c$ oxidase) foi fusionado com sequências alvos alternativas para endereçamento na mitocôndria e posteriormente realocado no genoma nuclear de uma linhagem $\Delta \operatorname{cox} 2$. Este processo possibilitou a expressão deste gene, porém sem restabelecimento da atividade respiratória. Uma mutação induzida no primeiro domínio transmembrana da sequência deste híbrido (COX2-sequência alvo) resultou na expressão do gene com uma massa molecular indicando a clivagem da sequência de endereçamento mitocondrial. Com a incorporação da proteína COX2 na mitocôndria observou-se um restabelecimento na atividade respiratória do mutante.

Inversamente, é possível expressar genes nucleares na mitocôndria, como foi o caso dos experimentos alotópicos realizados com biobalística em levedura, que possibilitaram transferir o gene $R I P 1$, de origem nuclear e envolvido na montagem do complexo $b c 1$, da organela. Tal evento permitiu obter cópias estáveis e funcionais de RIP1 na mitocôndria quando este foi inserido na região codificadora para o gene COX1. A estabilidade observada indicou ser esta região o provável local de origem do gene RIP1 antes de ser transferido para o núcleo evolutivamente (GOLIK et al., 2003). Embora técnicas alotópicas sejam possíveis de serem realizadas, existem algumas diferenças entre o genoma mitocondrial e o nuclear. No genoma mitocondrial o códon CUA é traduzido para o aminoácido treonina e UGA em triptofano. Já no genoma nuclear estes mesmos códons são respectivamente traduzidos no aminoácido leucina e em códon terminador (BONITZ et al., 1980). Em virtude das diferenças do código genético mitocondrial e nuclear, a expressão alotópica de genes deve ser feita considerando tais diferenças.

O genoma mitocondrial em animais possui 37 genes com algumas variações correspondentes a duplicações do material genético. Desse total de genes, 13 estão envolvidos na montagem de subunidades dos complexos respiratórios, 2 em rRNAs do ribossomo mitocondrial e os outros 22 em tRNAs necessários para a tradução de proteínas codificadas pelo DNA mitocondrial. Alguns animais como nemátodos e bivalves perderam o gene que codifica para a subunidade 8 da ATP sintase (ATP8), já 
os cnidários perderam quase todos os genes para tRNAs e ganharam 1 ou 2 genes adicionais não encontrados na maioria de outros DNAs mitocondriais (BOORE, 1999). Os 13 genes que codificam polipeptídeos envolvidos na montagem das subunidades dos complexos respiratórios estão distribuídos da seguinte forma: sete (ND 1, 2, 3, 4L, 4, 5, 6) que codificam proteínas do complexo I (NADH: ubiquinona oxidoredutase), o qual possui um total de 46 polipeptídeos. Um único gene (citocromo $b$, cyt $b$ ) que contribui para a formação do complexo III (complexo $b c_{1}$ ), composto por 11 polipepetídeos. As proteínas codificadas pelos três genes COI, II, III que fazem parte do complexo IV (citocromo $c$ oxidase), e, finalmente, dois genes mitocondriais, ATP 6 e 8, que contribuem com dois polipeptídeos dos 16 que compõem o complexo IV (ATP sintase) (WALLACE, 2005). Por inferência os mesmos genes estão provavelmente também presentes no genoma mitocondrial de plantas, fungos e protistas (BOORE, 1999; TZAGOLOFF e MYERS, 1986).

Estruturalmente a mitocôndria possui duas membranas: uma externa que envolve o conteúdo da organela e uma interna, que está em contato com uma região denominada matriz mitocondrial. As grandes invaginações promovidas pela membrana interna no interior da matriz recebem o nome de cristas mitocondriais (TZAGOLOFF, 1982). Nas cristas estão localizados os complexos respiratórios responsáveis pela captação de elétrons de substratos como $\mathrm{NADH}$ e $\mathrm{FADH}_{2}$ gerados pela oxidação de açúcares, ácidos graxos e proteínas. Em mamíferos e em muitos fungos o complexo I mitocondrial (NADH: ubiquinona oxidoredutase), constitui o maior complexo da cadeia respiratória com 42 subunidades diferentes. Em $S$. cerevisiae existem três diferentes isoformas de NADH: ubiquinona oxidoredutase que não constituem um complexo e não são inibidos por rotenona (GRANDIER-VAZEILLE et al., 2001). O complexo II (succinato: ubiquinona redutase), além de transferir elétrons recebidos da $\mathrm{FADH}_{2}$, também participa do ciclo de Krebs.

A transferência de elétrons dos complexos I, II e dos doadores orotato desidrogenase e acil-Coa desidrogenase para o complexo III da cadeia respiratória mitocondrial, dependem de uma molécula encontrada em praticamente todos os seres aeróbios: a coenzima Q (LÓPEZ-LLUCH et al., 2010). Esta molécula hidrofóbica está imersa na membrana interna da mitocôndria (LENAZ et al., 2007) e possui 10 genes nucleares envolvidos direta e indiretamente em sua biossíntese (revisto em TRAN e CLARKE, 2007). A coenzima Q (CoQ), assume a sua forma reduzida - o ubiquinol, que por sua vez transfere os elétrons para o complexo III (ubiquinol citocromo $c$ 
redutase). O complexo III possui como centros catalíticos o citocromo $b$, citocromo $c 1 \mathrm{e}$ o centro Fe-S de Rieske. A atividade redox do ubiquinol é acoplada à sua protonação e desprotonação que ciclicamente é utilizada pelo complexo III para a passagem de íons de hidrogênio para o espaço intermembrana. Do complexo III os elétrons são transferidos para o citocromo $c$, e este, por fim, doa os elétrons para o complexo IV (citocromo $c$ oxidase) o qual faz a redução do oxigênio em água (SARASTE, 1999). A citocromo $c$ oxidase possui como centros catalíticos os centros metálicos $\mathrm{Cu} A, \mathrm{CuB}$, os hemes $a$ e $a 3$ (BARRIENTOS et al., 2002).

Os complexos respiratórios utilizam a energia liberada pelo transporte eletrônico para o bombeamento de prótons da matriz mitocondrial para o espaço intermembranar. Forma-se um gradiente eletroquímico que força a volta dos prótons para a matriz mitocondrial pelo poro do complexo V (ATP sintase). A ATP sintase é composta por duas subunidades, uma fixa, $F_{0}$ e outra móvel, $F_{1}$. Quando os prótons passam pela subunidade $\mathrm{F}_{1}$, promovem rotação que possibilita a geração de uma força motriz, a qual é utilizada para a fosforilação do ADP em ATP (SARASTE, 1999).

O ATP é uma fonte de energia utilizada pelas células para executar atividades químicas, mecânicas e osmóticas. Os organismos anaeróbicos facultativos e obrigatórios sintetizam ATP a partir da oxidação da glicose à piruvato, resultando na produção de 2 mols de ATP por mol de glicose oxidada. Este processo de geração de ATP tornou-se mais sofisticado com o surgimento dos seres aeróbios, e conseqüente oxidação completa da glicose até $\mathrm{CO}_{2}$ e $\mathrm{H}_{2} \mathrm{O}$, e, como resultado, aperfeiçoou em 19 vezes a capacidade de produção de ATP (TZAGOLOFF, 1982).

\subsection{Produção de espécies reativas de oxigênio na mitocôndria}

Embora o oxigênio seja essencial para a produção de energia da célula e, consequentemente, para sobrevivência dos organismos aeróbicos, há um paradoxo em seu papel por causa dos subprodutos gerados durante a respiração celular. Derivados reativos tais como radicais hidroxil e superóxidos, peróxidos de hidrogênio e oxigênio singlet, podem ser formados e recebem o nome de Espécies Reativas de Oxigênio (EROs) (revisto em BENTINGER et al., 2007). O ânion superóxido $\left(\mathrm{O}_{2}^{-}\right.$) é o maior precursor das EROs e um mediador em reações oxidativas, sendo produto da redução de um elétron ao oxigênio. A dismutação de $\mathrm{O}_{2}{ }^{-}$. (espontaneamente ou por reações 
catalisadas por superóxidos dismutases) resulta em peróxido de hidrogênio $\left(\mathrm{H}_{2} \mathrm{O}_{2}\right)$ que pode ser completamente reduzido a água ou parcialmente reduzido no radical hidroxil $(\mathrm{OH} \cdot)$, um dos mais fortes oxidantes da natureza. A formação do hidroxil é catalizada por metais de transição reduzidos no qual podem ser novamente reduzidos pelo $\mathrm{O}_{2}{ }^{-}$e continuar propagando o processo (LIOCHEV e FRIDOVICH, 1998; TURRENS, 2003). A formação de EROs pode ocasionar danos oxidativos em proteínas, DNA e lipídeos sugerindo a sua participação em processos de envelhecimento e apoptose, bem como em doenças neurodegenerativas (GIBSON, 2005; HENSLEY e FLOYD, 2002; RABILLOUD et al., 2001; RAHA e ROBINSON, 2000; STADTMAN, 2001).

A mitocôndria é a principal fonte geradora de EROs, mas, aproximadamente, de 1 - 4\% de todo oxigênio consumido na cadeia respiratória é convertido em espécies reativas de oxigênio (ATTARDI, 2002). A implicação de que a mitocôndria é a principal produtora e alvo de EROs tem sido base para a teoria do envelhecimento mitocondrial inicialmente proposta em 1956 por Harman e defendida por vários autores que em estudos com fígado, músculo e cérebro de primatas associaram a redução de enzimas da cadeia transportadora de elétrons e o acúmulo de mutações no mtDNA, como resultado do aumentos de EROs (MELOV et al., 1995; TROUNCE et al., 1989; WALLACE, 1999). Os efeitos danosos de radicais superóxidos foram demonstrados em experimentos utilizando leveduras com alelos nulos para a enzima superóxido dismutase (uma enzima antioxidante) citosólica e mitocondrial. A avaliação de linhagens deficientes para estas enzimas indicou uma redução significativa do tempo de vida na fase estacionária promovida por esta espécie reativa de oxigênio (LONGO et al., 1999).

Existem sítios da cadeia respiratória mitocondrial que são considerados os principais responsáveis pela parcial redução do oxigênio a ânion superóxido: o complexo da NADH: ubiquinona oxidoredutase (complexo I), o qual provavelmente produz superóxidos através da autoxidação de uma flavina semiquinona da NADH desidrogenase, e o complexo do citocromo $b c 1$ (complexo III), o qual está envolvido na produção do radical ubisemiquinona (SUN e TRUMPOWER, 2003). O radical superóxido $\left(\mathrm{O}_{2}^{-}\right)$indicado na figura 1 , é uma molécula instável que associado com seu produto de dismutação, o $\mathrm{H}_{2} \mathrm{O}_{2}$, reage com outras macromoléculas (inclusive as do ciclo de Krebs) formando inúmeros compostos citotóxicos (SEDENSKY e MORGAN, 2006). Na mitocôndria também ocorre a geração do óxido nítrico (NO·) via reação da óxido nítrico sintase (NOS). $\mathrm{O}_{2}{ }^{-}$e $\mathrm{NO}$. reagem resultando em um outro oxidante, o 
peroxinitrito (ONOO·), o qual é uma fonte potencial para a produção do radical extremamente agressivo: o radical hidroxil (OH·) (GILCA et al., 2007; TURRENS, 2003).

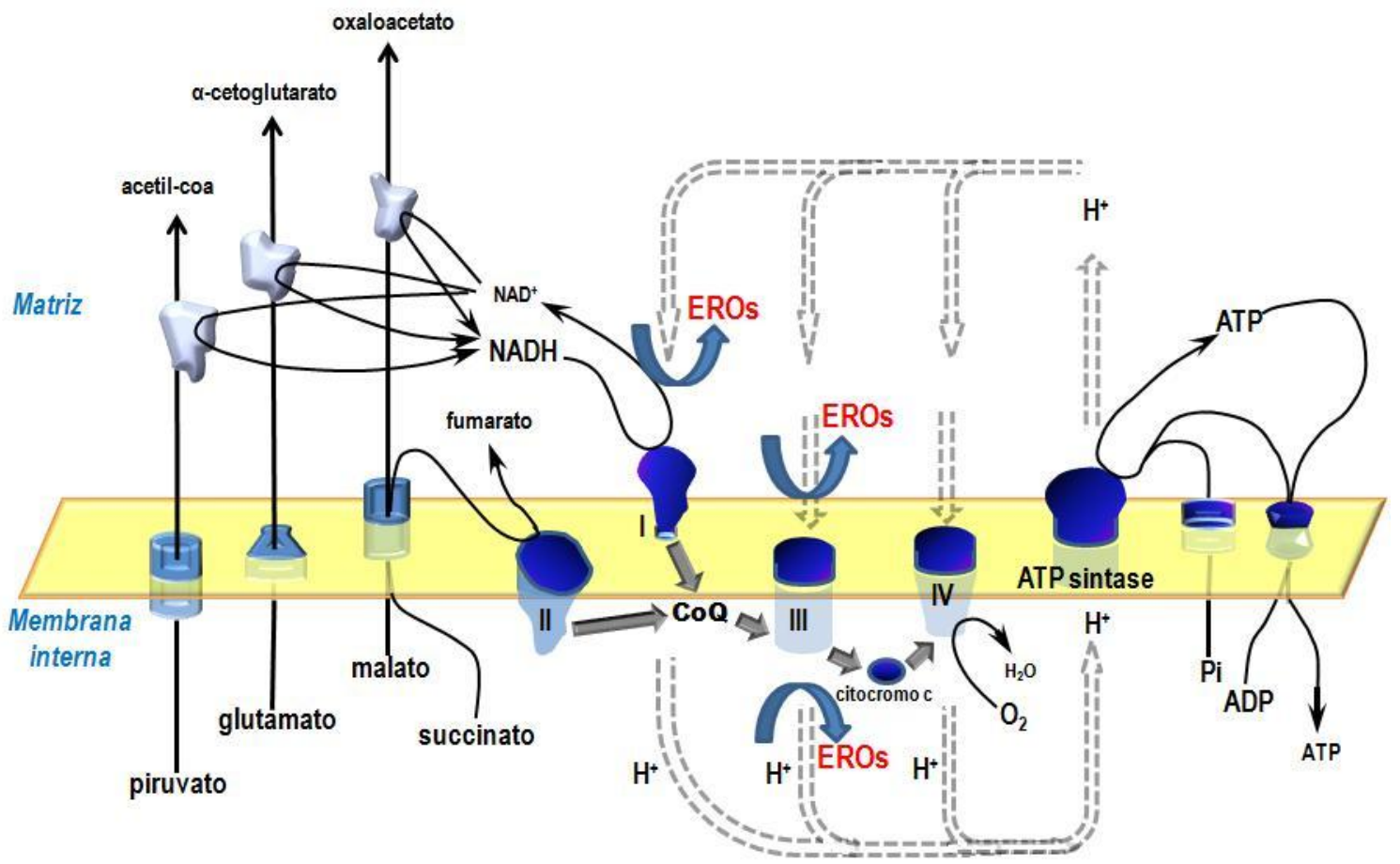

Espaço intermembrana

Figura 1. Etapas envolvidas no mecanismo de fosforilação oxidativa e os principais pontos de geração de espécies reativas de oxigênio na cadeia transportadora de elétrons mitocondrial. Substratos da cadeia respiratória são transportados através da membrana interna mitocondrial por seus respectivos transportadores. Elétrons do piruvato, glutamato e malato são transferidos para o $\mathrm{NAD}^{+}$e entram na cadeia respiratória via complexo I, que em conjunto com elétrons provenientes do complexo II a partir do succinato, doam para o complexo III via coenzima Q (CoQ). Finalmente os elétrons reagem com o oxigênio, o aceptor final, via citocromo $c$ e complexo IV. O fluxo eletrônico (setas planas cinzas) está associado a extrusão de prótons pelos complexos I, III e IV (setas planas pontilhadas). Prótons retornam do espaço intermembrana para a matriz através de uma ATP sintase, promovendo a produção de ATP. O ADP e o fosfato inorgânico (Pi), entram na matriz via ADP/ATP translocase e um transportador de fosfato. As setas azuis indicam os locais envolvidos na produção de EROs.

FONTE: Adaptado de Sedensky e Morgan (2006).

Foram identificados vários mecanismos de defesa naturais contra EROs, tais como: a superóxido dismutase dependente de manganês - MnSOD da matriz mitocondrial (WALLACE, 2005); superóxidos dismutases-zinco/cobre do espaço intermembrana (STURTZ et al., 2001); glutationa peroxidase e tioredoxina peroxidase e outras dismutases, presentes no citoplasma e no lado extracelular (FRIDOVICH, 1995). Estas enzimas atuam limitando os danos oxidativos induzidos por EROs, dismutando o $\mathrm{O}_{2}^{-}$a $\mathrm{H}_{2} \mathrm{O}_{2}$ o qual é então convertido em oxigênio e $\mathrm{H}_{2} \mathrm{O}$ pela glutationa peroxidase, 
tioredoxina peroxidase ou catalase (INOUE et al., 1999; SIES e MOSS, 1978). Glutationa e tioredoxina são importantes fontes de grupos tiol e sulfidril, respectivamente. Ambos atuam como doadores de elétrons para peroxidases dependentes de grupos tiol, sendo que estes grupos estão associados ao resíduo cisteinil da glutationa reduzida (GSH) que pode agir como um agente redutor ou nucleofílico para radicais livres evitando assim danos celulares (MEISTER e ANDERSON, 1983; MONTEIRO et al., 2004; REBRIN e SOHAL, 2008).

Um dos principais danos promovidos pelo excesso de radicais livres envolve a peroxidação de lipídeos (BENTINGER et al., 2007). Este processo consiste de três etapas: Na primeira etapa, denominada "iniciação", um átomo de hidrogênio é removido do grupo metil de um ácido graxo, resultando em um carbono centralizado - radical alquil (L·) que reage com o oxigênio promovendo a formação do radical peroxil (LOO·). Na segunda etapa chamada "propagação", LOO· remove um átomo de hidrogênio adicional de outro ácido graxo insaturado resultando em L. (radical) e hidroxiperóxido $(\mathrm{LOOH})$, este último pode ser reoxidado a LOO no qual reinicia a peroxidação dos lipídeos. A degradação de LOOH pode seguir várias vias metabólicas diferentes, resultando em hidrocarbonetos, alcoóis, éters, epóxidos e aldeídos. Ao contrário de outros produtos alguns aldeídos tais como malondialdeído e 4hidroxinomenal são de longa vida e podem se difundir do sítio de origem reagindo com fosfolipídeos, proteínas e DNA. A terceira e última fase é a "terminação", onde um produto não-radical é formado entre dois radicais (BENTINGER et al., 2007).

A oxidação de proteínas envolve um processo similar a peroxidação lipídica, onde $\mathrm{o} \mathrm{H}_{2} \mathrm{O}_{2}$ reage com um metal de transição ligado a proteína (cobre ou ferro), resultando em radicais hidroxil no sítio de ligação do metal (STADTMAN, 1993). O radical oxida aminoácidos individuais e a fase de propagação pode continuar em distintas direções, com a própria proteína, outra proteína, ou ainda com um lipídeo. Radicais livres derivados da peroxidação de lipídeos são também capazes de mediar a oxidação de proteínas. Finalmente, danos provocados no DNA também envolvem a presença de um metal de transição, tendo o DNA mitocondrial maior susceptibilidade desses danos devido a grande concentração de EROs nesta região (BENTINGER et al., 2007). Entretanto foi identificado a presença de nucleóides no genoma mitocondrial que amenizam os efeitos desses radicais, promovendo uma proteção pelo empacotamento do DNA semelhante as histonas do núcleo, bem como estabilizando o mtDNA (CHEN e BUTOW, 2005; KUCEJ e BUTOW, 2007). 
O fato de que a mitocôndria possui um aparato sofisticado de produção energética celular, que resulta na conversão do oxigênio consumido em espécies reativas de oxigênio (ATTARDI, 2002) explica a relação que existe entre mitocôndria e doenças. O DNA mitocondrial (mtDNA) possui uma taxa de mutação 10 vezes superior em relação a genes nucleares de simples cópia (BROWN et al., 1979² apud ATTARDI, 2002) e o fato de que o aumento de doenças neurodegenerativas está relacionado com o avanço da idade, pode ser explicado pelo acúmulo de mutações no genoma mitocondrial com a idade (GOGVADZE et al., 2009).

Estudos indicam a associação de diversas doenças humanas relacionadas com problemas mitocondriais, tais como: Parkinson, Alzheimer, Huntington, ataxia de Friedreich, diabetes e envelhecimento (DUCHEN, 2004; JAMES et al., 2005; MCKENZIE et al., 2004). Estima-se que a freqüência de doenças como Parkinson e Huntington seja na ordem de 18/100.000 e 3-7/100.000 habitantes respectivamente (GALPERN e CUDKOWICZ, 2007; GOGVADZE, 2009) estes valores podem ser preocupantes se considerarmos a associação dessas doenças com danos mitocondriais e pela alta frequência de mutação do DNA mitocondrial, 1/5.000 (SCHAEFER et al., 2004, 2007). Evidências de que mutações no DNA mitocondrial são fatores comuns na etiologia de doenças como o diabetes, foram propostas com base na identificação de uma mutação herdada maternalmente e localizada na posição 4291 ( T >C) do mtDNA. Esta região está envolvida com a codificação de um tRNA ${ }^{\text {Ile }}$ na mitocôndria humana e há relatos de envolvimento com a hipercolesterolemia, hipertensão e deficiência renal (WALLACE, 2005).

A formação de EROs pode ser monitorada por procedimentos como fluorometria, espectrofotometria, quimioluminiscência e ressonância paramagnética (CHANCE et al., 1979; POU et al., 1989; TARPEY e FRIDOVICH, 2001). Embora estes métodos sejam confiáveis, podem apresentar artefatos causados por espécies de similar reatividade ou por intermediários reativos produzidos pela própria sonda (revisto em TURRENS, 2003). Enzimas inibitórias específicas (superóxido dismutase, catalase etc.) podem ser aplicadas para cada radical estudado, porém, estas enzimas não

\footnotetext{
2 BROW, W. M.; GEORGE JR, M.; WILSON, A. C. Rapid evolution of animal mitochondrial DNA.
} Proc. Natl Acad. Sci. U.S.A., v. 76, p. 1967-1971, 1979. 
determinam se essas EROs são as fontes primárias ou intermediárias formadas durante a reação (TURRENS, 2003).

Embora a geração de EROs estejam associadas a inúmeros efeitos citotóxicos, há evidências que o ânion superóxido, peróxidos, monóxido de carbono e óxido nítrico, tem um papel essencial em uma variedade de processos fisiológicos, tais como a proliferação celular e diferenciação, regulação do gene e defesas antibacterianas (REBRIN e SOHAL, 2008). A expressão ectópica da catalase na matriz mitocondrial associada à superexpressão da $\mathrm{MnSOD}$, resulta na redução da produção de $\mathrm{H}_{2} \mathrm{O}_{2}$ mitocondrial, porém, reduz o tempo de vida em Drosophila (BAYNE et al., 2005). Estes dados sugerem que o aumento de antioxidantes não necessariamente retardam o processo de envelhecimento, o que confirma que a expressão regulada basal é fisiologicamente essencial.

\subsection{Coenzima $Q$}

\subsubsection{O papel biológico da Coenzima $Q$}

A coenzima Q ou ubiquinona em procariotos foi isolada e caracterizada em 1955 por Festenstein et al. e em 1957 Crane et al. estabeleceram que este composto é um membro da cadeia respiratória mitocondrial (TURUNEN et al., 2004). Em 1958, trabalhos realizados por Wolf et al. determinaram que a CoQ é constituída por um anel de benzoquinona com capacidade redox e ligado a uma cadeia poliprenil. O número de unidades de isoprenos na cadeia poliprenil é distinto em diferentes organismos; humanos produzem $\mathrm{CoQ}_{10}$, Caenorhabditis elegans $\mathrm{CoQ}_{9}$, Escherichia coli $\mathrm{CoQ}_{2} \mathrm{e}$ Saccharomyces cerevisiae $\mathrm{CoQ}_{6}$ (MARBOIS et al., 2005).

A confirmação da função da CoQ foi realizada durante a década de 1960 com experimentos empregando a $\mathrm{CoQ}_{2}$ na oxidação da difosfopiridina reduzida (DPNH). Neste experimento foi construído um sistema in vitro composto por DPNH-citocromo $c$ redutase, citocromo $c$ e citocromo oxidase e então avaliado a capacidade desse sistema de oxidar a DPNH. A elevada velocidade de oxidação da DPNH não foi considerada como uma simples colisão do transporte de elétrons do sistema, mas devido a coenzima Q adicionada (GREEN e HATEFI, 1961). Em 1975 o ciclo de regeneração da coenzima Q ficou estabelecido com a divulgação do ciclo Q próton-motivo proposto por Mitchell, sugerindo que a transferência de elétrons ocorre através do complexo III envolvendo 
uma ubisemiquinona (MITCHELL, 1975). Modificações posteriores identificaram um fluxo reverso de elétrons quando utilizado inibidores específicos deste ciclo. Esta reversão de elétrons promove a geração de superóxidos a partir do radical semiquinona que reduz o oxigênio molecular (SUN e TRUMPOWER, 2003).

O ciclo de regeneração da coenzima $Q$ inicia-se através da forma reduzida ubiquinol $\left(\mathrm{QH}_{2}\right)$, que transporta elétrons provenientes do complexo I e II, atravessando a membrana interna mitocondrial e fornecendo dois prótons para o espaço intermembrana (figura 2). Paralelamente, ocorre a transferência de um elétron para a proteína ferro-enxofre (FeS, proteína Rieske do complexo III) que posteriormente é transferido para o complexo $c_{1}$ e finalmente ao citocromo $c$. A semiquinona desprotonada resultante $\left(\mathrm{Q}^{-}\right)$é um tipo de radical livre tóxico e impermeável à membrana, logo, deve doar o segundo elétron para o grupo heme $b_{\mathrm{L}}$, formando uma quinona (Q) difusível (COVIAN et al., 2007; TRUMPOWER, 1990).

A utilização de inibidores específicos da cadeia respiratória, tais como a antimicina A e o mixotiazol constitui uma excelente ferramenta de estudo do comportamento do ciclo de regeneração da coenzima Q mitocondrial. A antimicina A liga-se no sítio $\mathrm{N}$ inibindo a redução da ubiquinona e do ânion semiquinona pelo citocromo $b_{\mathrm{H}}$. Como resultado desse bloqueio, ocorre um fluxo reverso de elétrons do citocromo $b_{\mathrm{L}}$ para a coenzima $\mathrm{Q}$ formando semiquinona (figura 2). Já o mixotiazol ligase próximo ao grupo heme do citocromo $b_{\mathrm{L}}$ no sítio $\mathrm{P}$ impedindo sua redução (COVIAN et al., 2007, 1999; STARKOV e FISKUM, 2001) porém, não forma pontes de hidrogênio com os resíduos de histidina da proteína ferro enxofre de Rieske (ZHANG et al., 1998). Como consequiência, o ubiquinol pode acessar o sítio da proteína de Rieske, mas não o sítio heme $b_{\mathrm{L}}$ na presença de mixotiazol, resultando na formação do ânion superóxido (SUN e TRUMPOWER, 2003). Esses dados são contrários àqueles inicialmente observados por von Jagow et al. (1984), no qual inferiram que o mixotiazol bloqueia a redução do citocromo $c_{1}$ mas não a redução do citocromo $b$ no qual ocorre fluxo reverso de elétrons no centro do sítio N. 


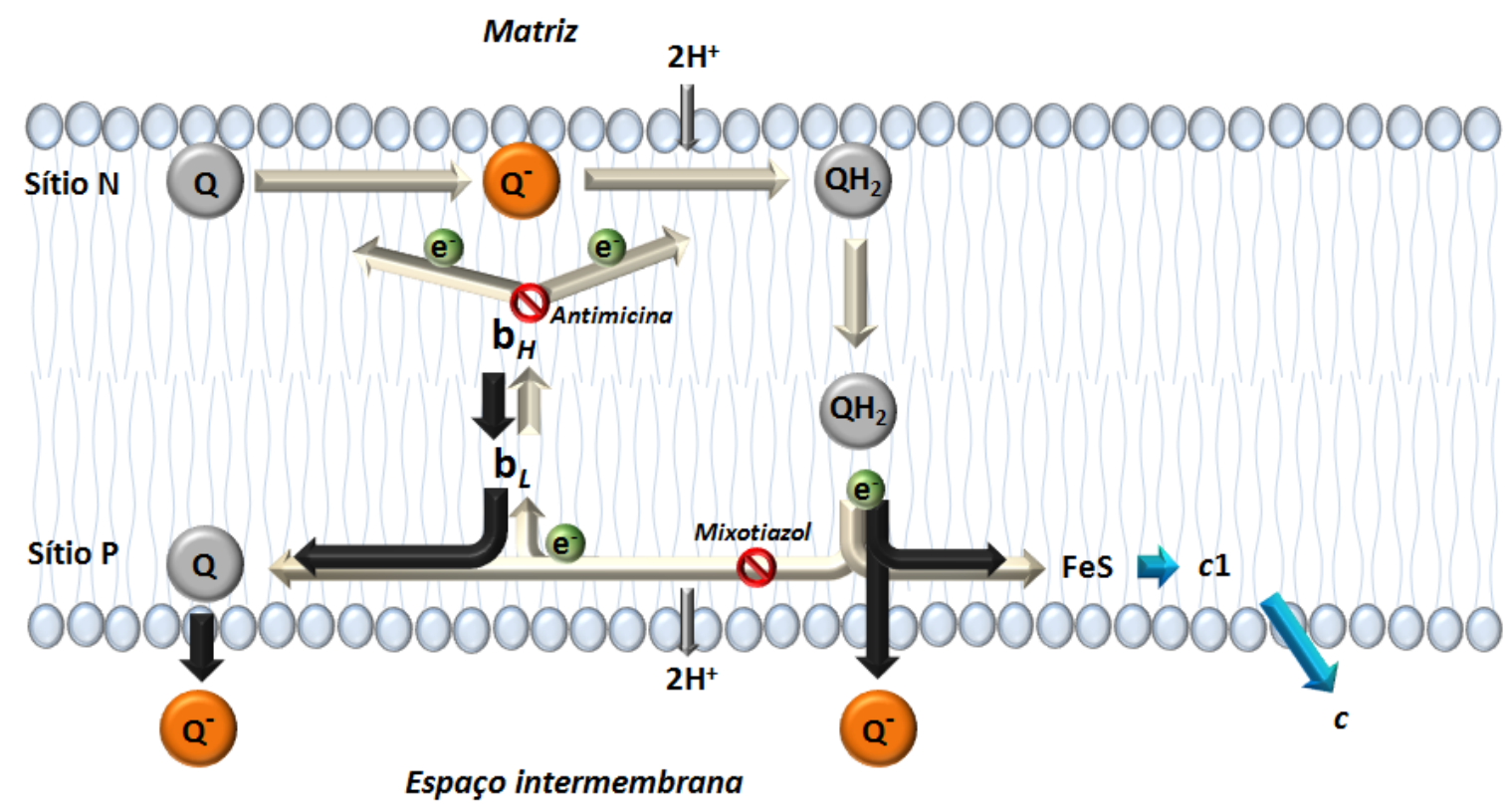

Figura 2. Esquema do ciclo de regeneração da coenzima $Q$ na membrana interna mitocondrial (Ciclo Q). No sítio $\mathrm{P}$ dois elétrons são transferidos do $\mathrm{QH}_{2}$ para a proteína ferro-enxofre e citocromo $b_{\mathrm{L}}$. O inibidor mixotiazol liga-se ao sítio $\mathrm{P}$ impedindo a transferência de elétrons para $b_{\mathrm{L}}$ mas pode atuar em um sistema bifurcado, transferindo um elétron para a proteína de Rieske. No sítio N, a coenzima Q é reduzida pelo citocromo $b_{\mathrm{H}}$, primeiro a semiquinona e então a $\mathrm{QH}_{2}$. Este passo é inibido pela antimicina A, que se liga ao sítio N. A seta escura indica a redução da coenzima $\mathrm{Q}$ a semiquinona no sítio $\mathrm{P}$ na presença de antimicina $\mathrm{A}$ ou mixotiazol. A semiquinona formada na presença de mixotiazol é resultante do bloqueio de elétrons para $b_{\mathrm{H}} \mathrm{e}$ baixa transferência para a proteína ferro-enxofre. Antimicina e mixotiazol,são inibidores específicos dos locais indicados. Q - ubiquinona; $\mathrm{Q}^{-}$- semiquinona; $\mathrm{QH}_{2}-$ ubiquinol; $\mathrm{FeS}$ Proteína Ferro Enxofre; $c_{1}$ e $c$ - citocromo $c_{1}$ e $c$ do complexo III mitocondrial.

FONTE: Ilustração adaptada de Trumpower (1990).

Sob determinadas condições, o ciclo Q pode ser alterado por rotas alternativas, do tipo "bypass", acarretando distúrbios fisiológicos, tais como a produção de superóxidos. Esse tipo de reação ocorre in vitro e em condições parcialmente inibidas na presença de antimicina $\mathrm{A}$. Uma vez adicionada antimicina $\mathrm{A}, \mathrm{QH}_{2}$ é oxidado a $\mathrm{Q}^{-}$pelo centro FeS, porém, o processamento de elétrons através do baixo potencial da cadeia respiratória é inibido, resultando no acúmulo do radical Q Q que reduz $\mathrm{O}_{2}$ em superóxido (FORQUER et al., 2006).

Além da participação na transferência de elétrons da cadeia respiratória mitocondrial, Turunen et al. (2004), revisaram outras funções importantes da coenzima Q nos mecanismos celulares: 1) participação no transporte extramitocondrial de elétrons na membrana plasmática e em lisossomos (GILLE e NOHL, 2000; KISHI et al., 1999); 2) sintetizada endogenamente, atua como um antioxidante solúvel em lipídeos 
(MELLORS e TAPPEL, 1966; TAKAYANAGI et al., 1980); 3) está envolvida na regulação da permeabilidade mitocondrial, através de poros de transição e na regulação das propriedades físico-químicas da membrana (FONTAINE et al., 1998; WALTER et al., 2000); 4) é requerida para a ativação de proteínas desacopladoras (ECHTAY et al., 2000, 2001) e 5) está envolvida na modulação da quantidade de $\beta 2$-integrinas na superfície dos monócitos do sangue (WITTING et al., 2000). Também foram encontradas associações nos mecanismos de oxidação de sulfito (em leveduras) e na introdução de pontes dissulfito em bactérias (TURUNEN et al., 2004).

O paradoxo pró-oxidante/antioxidante exercido pela $\mathrm{CoQ}$ sugere que esta molécula atue como um modulador do estado redox sob condições fisiológicas/patológicas, sugerindo sua participação no mecanismo de envelhecimento. Segundo Sohal (2002), durante o envelhecimento há uma mudança pró-oxidante no estado redox celular, isso desencadeia um aumento de danos oxidativos em inúmeras moléculas que em combinação tem um papel importante na senescência.

\subsubsection{A biossíntese da Coenzima $Q$}

A compreensão da biossíntese da CoQ tem sido obtida, ao longo dos anos, graças a estudos em E. coli e S. cerevisiae. Em procariotos, a biossíntese de CoQ (figura 3) envolve modificações no anel benzoquinona após a ligação da cadeia isoprenóide através de uma descarboxilação seguida de hidroxilação e metilação, por outro lado em eucariotos a descarboxilação ocorre após a hidroxilação e metilação (TURUNEN et al., 2004). Os estudos genéticos na levedura $S$. cerevisiae levaram a identificação de nove grupos de complementação (COQ1-COQ9) atuando diretamente na montagem da coenzima Q (JOHNSON et al., 2005; TRAN e CLARKE, 2007; TZAGOLOFF e DIECKMANN, 1990), e um décimo gene (COQ10) foi descoberto com características distintas dos demais identificados (BARROS et al., 2005). 
A elucidação da via biossintética da coenzima Q é derivada da caracterização de intermediários acumulados em linhagens mutantes, deficientes em CoQ de $S$. cerevisiae e E. coli (TRAN e CLARKE, 2007; MEGANATHAN, 2001). Na figura 3 está esquematizado o processo de biossíntese da CoQ em $S$. cerevisiae com os seus respectivos genes envolvidos e outros ainda sem funções conhecidas. A biossíntese inicia-se a partir da formação de um grupo de ácido hidroxibenzóico e uma cadeia

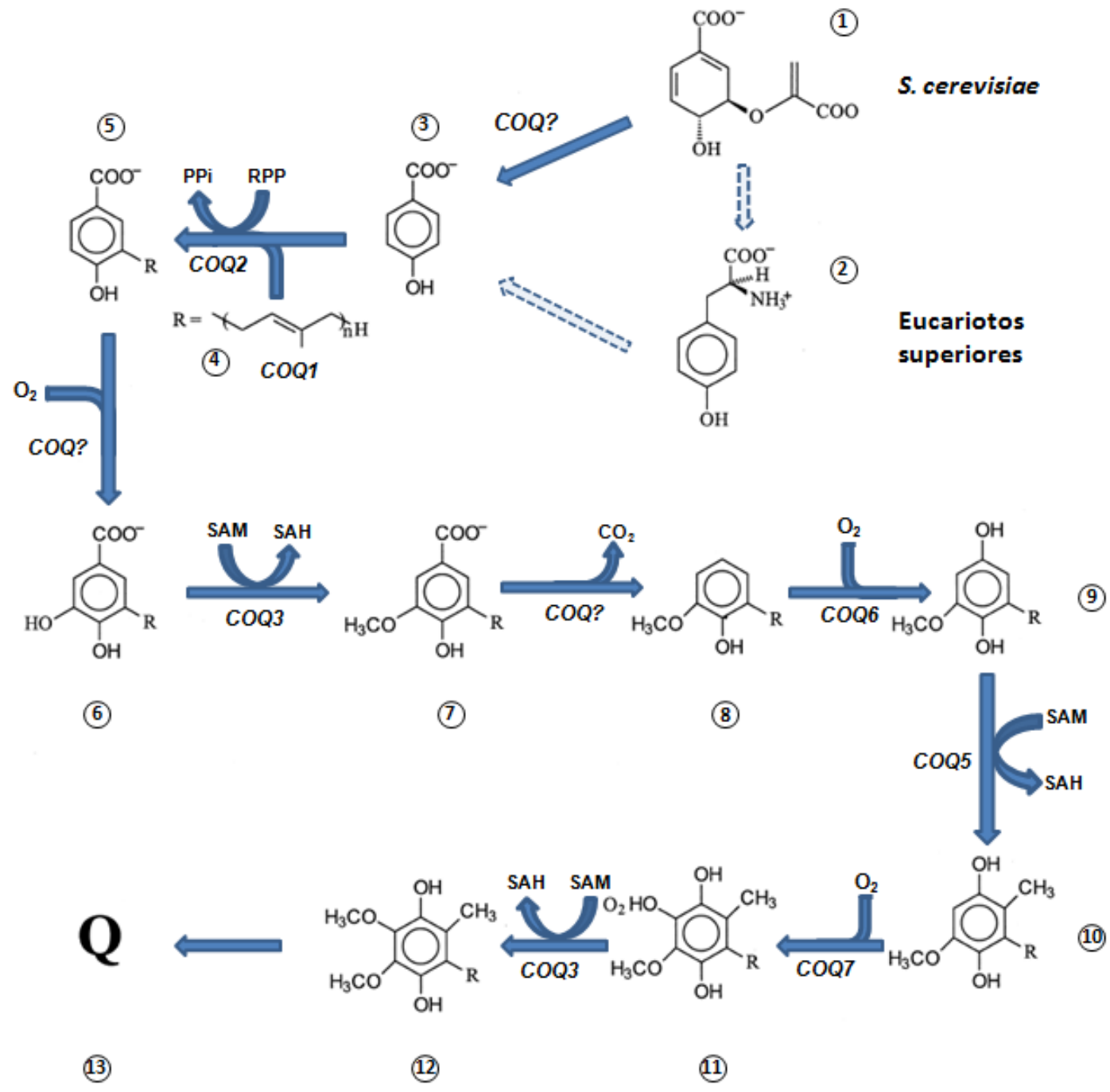

Figura 3. Biossíntese da ubiquinona em $S$. cerevisiae e outros eucariotos. Os intermediários da via biossintética são: 1) corismato; 2) tirosina; 3) 4-hidroxibenzoato; 4) cadeia poliprenil ( $S$. cerevisiae $=$ hexaprenil); 5) 3-poliprenil-4-hidroxibenzoato; 6) 4-dihidroxi-5poliprenilbenzoato; 7) 3-metoxi-4-hidroxi-5-poliprenilbenzoato; 8) 2-poliprenil-6-metoxifenol; 9) 2-poliprenil-6-metoxi-1,4-benzoquinol; 10) 2-poliprenil-3-metil-6-metoxi-1,4-benzoquinol; 11) 2-poliprenil-3-metil-5-hidroxi-6-metoxi-1,4-benzoquinol; 12) Ubiquinol; 13) Ubiquinona. A conversão do ubiquinol a ubiquinona é catalizada por uma reação não enzimática.

FONTE: Adaptado de Meganathan (2001).

lipofílica polisoprenóide. O precursor aromático do anel benzoquinona do ácido 4hidroxibenzóico (4-HB) é derivado da tirosina, um aminoácido essencial em mamíferos. 
Em levedura, o 4-HB pode ser sintetizado na via do corismato (GOEWERT, $1980^{3}$ apud TRAN e CLARKE, 2007), pela corismato piruvato liase (reação similar ocorre em $E$. coli) ou, alternativamente, através da tirosina, processo realizado por eucariotos superiores (MEGANATHAN, 2001). As unidades para a síntese da cadeia polisoprenóide são providas pelo dimetil difosfato e isoprenil difosfato. Tanto em levedura quanto em mamíferos, estes precursores de cinco carbonos são derivados a acetil-coenzima A através da via do mevalonato (GRUNLER et al., 1994). Na tabela 1 estão descritos os nove genes envolvidos diretamente na biossíntese da coenzima Q com suas respectivas funções.

Tabela 1 - Genes envolvidos na biossíntese da coenzima $\mathrm{Q}_{6}$ de Saccharomyces cerevisiae. A função dos genes $C O Q 4, C O Q 8, C O Q 9$ e $C O Q 10$ não é conhecida.

\begin{tabular}{|c|c|c|}
\hline Gene & Função & Referência \\
\hline$C O Q 1$ & $\begin{array}{l}\text { Síntese da cadeia de isoprenos pela enzima } \\
\text { trans poliprenil difosfato a partir de } \\
\text { precursores da via do mevalonato. }\end{array}$ & $\begin{array}{l}\text { (ASHBY e EDWARDS, 1990; } \\
\text { MEGANATHAM, 2001) }\end{array}$ \\
\hline $\mathrm{COQ2}$ & $\begin{array}{l}\text { Ligação da cadeia de isoprenos ao anel } \\
\text { benzoquinona pela 4-HB polipreniltransferase. }\end{array}$ & $\begin{array}{l}\text { (ASHBY et al., 1992; } \\
\text { LEUENBERGER et al., 1999) }\end{array}$ \\
\hline COQ3 & $\begin{array}{c}\text { Enzima que atua como uma metiltransferase no } \\
\text { anel benzoquinona utilizando-se a } \\
\text { adenosilmetionina (SAM) como fonte de } \\
\text { grupos metila. }\end{array}$ & $\begin{array}{l}\text { (CLARKE et al., 1991; } \\
\text { POON et al., 1999) }\end{array}$ \\
\hline COQ4 & Não determinada. & (BELOGRUDOV et al., 2001) \\
\hline COQ5 & $\begin{array}{c}\text { Atua como uma metiltransferase no anel } \\
\text { benzoquinona. }\end{array}$ & (BARKOVICH et al., 1997) \\
\hline COQ6 & $\begin{array}{c}\text { Uma C-hidroxilase atuando como } \\
\text { monoxigenase dependente de flavina } \\
\text { adicionando grupos hidroxi no anel benzênico. }\end{array}$ & (GIN et al., 2003) \\
\hline $\operatorname{COQ7}$ & $\begin{array}{l}\text { Hidroxilação do 5-demetoxiubiquinol } \\
\left(\mathrm{DMQH}_{2}\right) \text {. }\end{array}$ & (MARBOIS e CLARKE, 1996) \\
\hline COQ8 & Não determinada. & $\begin{array}{l}\text { (BOUSQUET et al., 1991; } \\
\text { DO et al., 2001) }\end{array}$ \\
\hline $\operatorname{COQ} 9$ & Não determinada. & (JOHNSON et al., 2005) \\
\hline COQ10 & Não determinada. & (BARROS et al., 2005) \\
\hline
\end{tabular}

${ }^{3}$ GOEWERT, R. R. Studies on the Biosynthesis of Ubiquinone. St. Louis: S. Louis Univ., MO., 1980. 
MARBOIS et al., 2005). Análises eletroforéticas de sobrenadantes mitocondriais, solubilizados com digitonina, indicaram que Coq2p, Coq3p, Coq4p, Coq7p e Coq9p comigram como um complexo de alta massa molecular (HSIEH et al., 2007; TRAN et al., 2006). Além disso, Marbois et al. (2005) verificaram uma interação física entre os polipeptídeos Coq3p e Coq4p empregando a técnica de co-precipitação com a proteína Coq3p marcada com biotina. Estas evidências sugerem a formação de um complexo multi-subunidades para a síntese da coenzima Q, localizado no lado da matriz da membrana interna mitocondrial, tendo a proteína Coq2p como âncora desses polipeptídeos (TRAN e CLARKE, 2007).

O estudo de novos genes envolvidos na biossíntese da coenzima Q tem atraído maior atenção pelos pesquisadores, principalmente após trabalhos que associaram desordens mitocondriais com genes humanos para a biossíntese de CoQ. LagierTourenne et al. (2008) encontraram, em pacientes com manifestações clínicas de ataxia cerebelar e elevados níveis de lactato, uma mutação no gene contendo um domínio kinase 3 (ADCK3). Este gene é homólogo a COQ8 em levedura. A análise de fibroblastos demonstrou níveis endógenos baixos de $\mathrm{CoQ}_{10}$ em 3 dos 4 pacientes analisados, indicando a deficiência na biossíntese de coenzima $\mathrm{Q}_{10}$. Outra mutação encontrada em humanos envolvendo um gene da biossíntese de CoQ, foi divulgado por Duncan et al. (2009). Estes autores identificaram em um paciente com cardiomiopatia hipertrófica e disfunção tubular renal, uma mutação do tipo "stop codon" em uma região altamente conservada no gene $C O Q 9$. Os resultados quantitativos de coenzima $\mathrm{Q}_{10}$ obtidos por HPLC (Cromatografia Líquida de Alto Desempenho) demonstraram uma grave deficiência na produção dessa coenzima com presença do intermediário de sua biossíntese (HHB). Desta forma, torna-se estritamente necessário a compreensão funcional desses novos genes, uma vez que estão associados a patologias humanas.

Uma característica comum dos mutantes coq3-9 de S. cerevisiae é a ausência de CoQ e o acúmulo do intermediário ácido 3-hexaprenil-4-dihidroxibenzóico (HHB) (exceto para alguns mutantes pontuais de $\operatorname{coq} 7$ que acumulam demetoxi-Q ${ }_{6}$ ) (DO et al., 2001; MARBOIS e CLARKE, 1996; PADILLA et al., 2004). A presença de HHB é resultante de um bloqueio bioquímico em qualquer passo subseqüente à formação deste intermediário e segundo Johnson et al. (2005), pode sugerir três hipóteses: 1) a maioria dos intermediários da via são instáveis e degradados; 2) a via é altamente regulada e 3) as enzimas estão organizadas em um complexo, no qual é altamente sensível em qualquer um de seus componentes. A última hipótese é apoiada por estudos recentes 
que indicam uma interdependência de algumas proteínas Coq para sua estabilidade (GIN e CLARKE, 2005). Análises eletroforéticas em gel de poliacrilamida (2D) possibilitaram identificar um complexo de $500 \mathrm{kDa}$ constituído pelas proteínas Coq8p, Coq2p e Coq10p e outro complexo de 1.3 MDa com as proteínas Coq3p, Coq5p e Coq9p. Embora as proteínas Coq8p e Coq3p foram encontradas em complexos separados neste experimento, observou-se que a perda de Coq8p resulta na desestabilização da proteína Coq3p, confirmando uma interdependência dessas proteínas (TAUCHE et al., 2008).

\subsection{0 gene $C O Q 10$}

O avanço no estudo de ORFs hipotéticas por diversos grupos de pesquisa, desde o término do projeto genoma de levedura, em 1996 (GOFFEAU et al., 1996), demonstra o enorme interesse nesse tipo de estudo. Nesse contexto foram descritas as ORFs YLR201W e YOL008W como necessárias para a expressão funcional da coenzima $\mathrm{Q}_{6}$ de levedura, as quais foram renomeadas de $C O Q 9$ e $C O Q 10$ respectivamente (JOHNSON et al., 2005; BARROS et al., 2005). Estudos envolvendo a deleção da ORF YOLO08W no cromossomo XV de $S$. cerevisiae resultou em uma linhagem deficiente respiratório devido a uma deficiência no mecanismo de oxidação da NADH e do succinato na mitocôndria (BARROS et al., 2005). Esta característica é peculiar para todos os mutantes coq, podendo ser restaurada adicionando-se coenzima $\mathrm{CoQ}_{2}$ exógena (TZAGOLOFF et al., 1975). Mas diferentemente dos demais mutantes coq, a deleção da ORF YOLO08W resultou em uma linhagem deficiente respiratória que não acumula o intermediário HHB e que apresenta quantidades endógenas normais de $\mathrm{CoQ}_{6}$. Esta ORF foi nomeada $C O Q 10$, o último gene descoberto até o momento envolvido na biossíntese da coenzima $\mathrm{Q}_{6}$ (BARROS et al., 2005).

Análises de homologias estruturais possibilitaram classificar Coq10p como homólogo de CC1736 de Caulobacter crescentus, descrito como um membro da família PF03364 associado com poliketideos sintases/ciclases (SHEN et al., 2005). Embora CC1736 não demonstre significativa similaridade na seqüência primária de aminoácidos com membros da superfamília START (StAR - Steroidogenic Acute Regulatory protein), análises de algoritmos das dobras estruturais da proteína e de ressonância magnética nuclear (NMR) permitiram inferir como membro deste grupo. Proteínas 
START são constituídas por um túnel hidrofóbico e estão envolvidas em ligações com compostos lipofílicos e no transporte de esteróides através da membrana (AKIYAMA et al., 1997; VAN LOON et al., 1986). Análises estruturais da proteína também identificaram cinco resíduos de aminoácidos conservados evolutivamente e que provavelmente estão associados na especificidade de ligação com o substrato (SHEN et al., 2005). A confirmação de que Coq10p é uma proteína que atua indiretamente na biossíntese da coenzima Q ligando-se a esta molécula, foi confirmada pela presença de $\mathrm{CoQ}_{6}$ em preparações purificadas de Coq10p-6xHis em $S$. cerevisiae (BARROS et al., 2005) e complementando estes achados, estudos com as leveduras S. cerevisiae e, Schizosaccharomyces pombe possibilitaram encontrar em mutantes pontuais de COQ10 resíduos de aminoácidos importantes envolvidos na ligação com $\mathrm{CoQ}_{6}$ (BUSSO et al., 2010; CUI et al., 2008).

Coq10p é uma proteína de $24 \mathrm{kDa}$ localizada na membrana interna mitocondrial, do lado da matriz, existindo, provavelmente, como um homo-oligômero ou complexada com outras proteínas. Este fato é evidenciado pelo tamanho de cinco vezes maior da proteína nativa quando comparada ao monômero. Além disso, Coq10p sedimenta diferentemente de Coq3p ou Coq5p em gradiente de sacarose (BARROS et al., 2005). Outra característica importante é a capacidade de $C O Q 2$, $C O Q 7$ e $C O Q 8$, quando em altas cópias, de restaurarem o crescimento do mutante $\triangle$ coq10 (BARROS et al., 2005).

Embora $C O Q 10$ seja necessário para a função da coenzima $\mathrm{Q}_{6}$, a função exata desempenhada pelo seu produto gênico ainda não está completamente esclarecida. A presença de $\mathrm{CoQ}_{6}$ contrasta com a deficiência da passagem de elétrons para o complexo $b c 1$ observadas em mutantes para este gene e necessita de maiores estudos quanto ao envolvimento de Coq10p no estresse oxidativo mitocondrial. As evidências de similaridade com membros de domínio START e a presença de $\mathrm{CoQ}_{6}$, sugerem a provável participação de Coq10p no transporte de $\mathrm{CoQ}_{6}$ mitocondrial em S. cerevisiae. 


\section{CONCLUSÕES}

1 - A ausência de coenzima $\mathrm{Q}_{6}$ nos mutantes coq1-9 além de promover deficiência respiratória, aumenta significativamente a geração de $\mathrm{H}_{2} \mathrm{O}_{2}$ reduzindo a viabilidade celular como foi verificado pela oxidação de ácidos graxos polinsaturados.

2 - Mutantes coq10 respondem a antimicina A indicando a atividade do ciclo de regeneração da coenzima $\mathrm{Q}_{6}$ e confirmado pela presença de semiquinona nos experimentos de ressonância magnética. Ficou evidente que o fluxo de elétrons ocorre até o citocromo $b_{\mathrm{L}}$, porém a mesma via é deficiente para a proteína Rieske como verificado pela baixa atividade de NADH-citocromo $c$ redutase.

3 - Mutações sítio dirigidas em Coq10p induziram a formação de linhagens com deficiência respiratória mitocondrial, indicando prováveis pontos estratégicos de ligação da proteína à coenzima $\mathrm{Q}_{6}$.

4 - Ensaios de modelagem molecular confirmaram a homologia de Coq10p com a proteína CC1736 de C. crescentus. A relação estrutural com esta proteína infere que Coq10p apresenta um domínio START implicado na ligação de moléculas lipofílicas, tais como provavelmente a coenzima $\mathrm{Q}$. 


\section{REFERÊNCIAS ${ }^{4}$}

ADAMS, K. L.; PALMER, J. D. Evolution of mitochondrial gene content: gene loss and transfer to the nucleus. Mol. Phyl. Evol., v. 29, p. 380-395, 2003.

ALLEN, J. F.; RAVEN, J. A. Free-Radical-Induced Mutation vs Redox Regulation: Costs and Benefits of Genes in Organelles. J. Mol. Evol., v. 42, p. 482-492, 1996.

AKIYAMA, N.; SASAKI, H.; ISHIZUKA, T.; KISHI, T., SAKAMOTO, H.; ONDA, M.; HIRAI, H.; YAZAKI, Y.; SUGIMURA, T.; TERADA. M. Isolation of a candidate gene, CAB1, for cholesterol transport to mitochondria from the c-ERBB-2 amplicon by a modified cDNA selection method. Cancer Res., v. 57, p. 3548-3553, 1997.

ANDERSSON, S. G. E.; KARLBERG, O.; CANBÄCK, B.; KURLAND, C. G. On the origin of mitochondria: a genomics perspective. Phil. T. R. Soc. B., v. 358, p. 165-179, 2002.

ASHBY, M. N.; EDWARDS, P. A. Elucidation of the deficiency in two yeast coenzyme Q mutants. Characterization of the structural gene encoding hexaprenyl pyrophosphate synthetase. J. Biol. Chem., v. 265, p. 13157-13164, 1990.

ASHBY, M.N.; KUTSUNAI, S. Y.; ACKERMAN, S.; TZAGOLOFF, A.; EDWARDS, P.A. COQ2 is a candidate for the structural gene encoding para-hydroxybenzoate: polyprenyltransferase. J. Biol. Chem., v. 267, p. 4128-4136, 1992.

ATTARDI, G. Role of mitochondrial DNA in human aging. Mitochondrion, v. 2, p. 27-37, 2002.

BABCOCK, M.; DE SILVA, D.; OAKS, R.; DAVIS-KAPLAN, S.; JIRALERSPONG, S.; MONTERMINI, L.; PANDOLFO, M.; KAPLAN, J. Regulation of mitochondrial iron accumulation by Yfh1p, a putative homolog of frataxin. Science, v. 276, p. 17091712, 1997.

BARKOVICH, R. J.; SHTANKO, A.; SHEPHERD, J. A.; LEE, P. T.; MYLES, D. C.; TZAGOLOFF, A.; CLARKE, C. F. Characterization of the COQ5 gene from Saccharomyces cerevisiae. Evidence for a C-methyltransferase in ubiquinone biosynthesis. J. Biol. Chem., v. 272, p. 9182-9188, 1997.

BARRIENTOS, A. In vivo and in organelle assessment of OXPHOS activities. Methods, v. 26, p. 307-316, 2002.

BARRIENTOS, A. Yeast Models of Human Mitochondrial Diseases. IUBMB Life, v. 55, p. 83-95, 2003.

\footnotetext{
${ }^{4}$ De acordo com: ASSOCIAÇÃO BRASILEIRA DE NORMAS TÉCNICAS.NBR 6023: Informação e documentação: referências: elaboração. Rio de Janeiro, 2002.
} 
BARROS, M. H.; JOHNSON, A.; GIN, P., MARBOIS, B. N.; CLARKE, C. F.; TZAGOLOFF, A. The Saccharomyces cerevisiae COQ10 gene encodes a START domain protein required for function of coenzyme Q in respiration. J. Biol. Chem., v. 280, p. 42627-42635, 2005.

BARROS, M. H.; BANDY, B.; TAHARA, E. B.; KOWALTOWSKI, A. J. Higher respiratory activity decreases mitochondrial reactive oxygen release and increases life span in Saccharomyces cerevisiae. J. Biol. Chem., v. 279, n. 48, p. 49883-49888, 2004.

BARROS, M. H.; NETTO, L. E. S.; KOWALTOWSKI, A. J. $\mathrm{H}_{2} \mathrm{O}_{2}$ generation in Saccharomyces cerevisiae respiratory PET mutants: effect of cytochrome C. Free Radical Bio. Med., v. 35, n. 2, p. 179-188, 2003.

BATEMAN, A.; BIRNEY, E.; CERRUTI, L.; DURBIN, R.; ETWILLER, L.; EDDY, S.R.; GRIFFITHS-JONES, S.; HOWE, K.L.; MARSHALL, M.; SHONNHAMMER, E. L. The Pfam protein families database. Nucleic Acids. Res., v. 30, p. 276-280, 2002.

BAYNE, A. C.; MOCKETT, R. J.; ORR, W. C.; SOHAL, R. S. Enhanced catabolism of mitochondrial superoxide/hydrogen peroxide and aging in transgenic Drosophila Biochem. J., v. 391, p. 277-284, 2005.

BELOGRUDOV, G. I.; LEE, P. T.; JONASSEN, T.; HSU, A. Y.; GIN, P.; CLARKE, C. F. Yeast COQ4 endocodes a mitochondrial protein required for coenzyme $Q$ synthesis, Arch. Biochem. Biophys., v. 392, p. 48-58, 2001.

BENTINGER, M.; BRISMAR, K.; DALLNER, G. The antioxidant role of coenzyme Q. Mitochondrion, v. 7S, p. S41-S50, 2007.

BIRBOIM, H. C.; DOLLY, J. A rapid alkaline extraction procedure for screening recombinant plasmid DNA. Nucleic Acids Res., v. 7: p. 1513-1523, 1979.

BOMMAKANTI, A. S.; KINDAHL, L.; ZENGEL, J. M. Mutation from guanine to adenine in 25S rRNA at tha position equivalent to E. coli A2058 does not confer erythromycin sensitivity in Saccharomyces cerevisiae. R.N.A., v. 14, p. 460-464, 2008.

BONITZ, S. G.; BERLANI, R.; CORUZZI, G.; LI, M.; MACINO, G.; NOBREGA, F. G.; NOBREGA, M. P.; THALENFELD, B. E.; TZAGOLOFF, A. Codon recognition rules in yeast mitochondria. Proc. Natl. Acad. Sci. U.S.A., v. 77, n. 6, p. 3167-3170, 1980.

BOORE, J. L. Animal mitochondrial genomes. Nucleic Acids Res., v. 27, n. 8, p. 1767-1780, 1999.

BOUSQUET, I.; DUJARDIN, G.; SLONIMSKI, P. P. Abc1, a novel yeast nuclear gene has a dual function in mitochondria: it suppresses a cytochrome $b$ mRNA translation defect and is essential for the electron in the bc1 complex. EMBO J., v. 10, p. 20232031, 1991. 
BOVERIS, A.; CHANCE, B. The Mitochondrial Generation of Hydrogen Peroxide. Biochem. J., v. 134, p. 707-716.

BROW, W. M.; GEORGE JR, M.; WILSON, A. C. Rapid evolution of animal mitochondrial DNA. Proc. Natl Acad. Sci. U.S.A., v. 76, p. 1967-1971, 1979.

BUSSO, C.; BLEICHER, L.; FERREIRA-JÚNIOR, J. R.; BARROS, M. H. Sitedirected mutagenesis and structural modeling of Coq10p indicate the presence of a tunnel for coenzyme Q6 binding. FEBS Lett., v. 584, p. 1609-1614, 2010.

CAMPUZANO, V.; MONTERMINI, L.; MOLTO, M. D.; PIANESE, L.; COSSESE, M.; CAVALCANTI, F.; MONROS, E.; RODIUS, F.; DUCLOS, F.; MONTICELLI, A. et al. Friedreich's ataxia: autosomal recessive disease caused by an intronic GAA triplet repeat expansion. Science, v. 271, p. 1423-1427, 1996.

CHANCE, B.; SIES, H.; BOVERIS, A. Hydroperoxide metabolism in mammalian organs. Physiol. Rev., v. 59, p. 527-605, 1979.

CLARKE, C. F.; WILLIAMS, W.; TERUYA, J. H. Ubiquinone biosynthesis in Saccharomyces cerevisiae. Isolation and sequence of COQ3, the 3,4-dihydroxy-5hexaprenylbenzoate methyltransferase gene. J. Biol. Chem., v. 266, p. 16636-16644, 1991.

COMBET, C.; JAMBON, M.; DELÉAGE, G.; GEOURJON, C. Geno3D: automatic comparative molecular modeling of protein. Bioinformatics, v. 18, p. 213-214, 2002.

COOPER, J. M.; SCHAPIRA, A. H. V. Friedreich's ataxia: Coenzyme $\mathrm{Q}_{10}$ and vitamin E therapy. Mitochondrion, v. 7S, p. S127-S135, 2007.

COVIAN, R.; ZWICKER, K.; ROTSAERT, F. A.; TRUMPOWER, B. L. Asymetric and Redox-specific Binding of Quinone and Quinol at Center N of the Dimeric Yeast Cytochrome bc1 Complex. J. Biol. Chem., v. 282, n. 33, p. 24198-24208, 2007.

CRANE, F. L.; HATELFI, Y.; LESTER, R. L.; WIDMER, C. Isolation of a quinine from beef heart mitochondria. Biochim. Biophys. Acta, v. 25, p. 220-221, 1957.

CUI, T. Z.; KAWAMUKAI, M. Coq10, a mitochondrial coenzyme Q binding protein, is required for proper respiration in Sachizosaccharomyces pombe. FEBS J., v. 276, p. 748-759, 2008.

DAVIES, K, J. A.; HOCHSTEIN, P. Ubisemiquinone radicals in liver: implications for a mitochondrial Q cycle in vivo. Biomed. Phys. Res. Commun., v. 107, n. 4, p. 12921299, 1982.

DAVIDSON, J. F.; SCHIESTL, R. H. Mitochondrial respiratory electron carriers are involved in oxidative stress during heat stress in Saccharomyces cerevisiae. Mol. Cell. Biol., v. 24, p. 8483-8489, 2001.

DELANO, W. L. The PyMol Molecular Graphics System. San Carlos, CA: DeLano Scientific, 2002. 
DEMASI, A. P.; PEREIRA, G. A.; NETTO, L.E. Yeast oxidative stress response. Influences of cytosolic thioredoxin peroxidase $\mathrm{I}$ and of the mitochondrial functional state. FEBS. J., v. 273, p. 805-816, 2001.

DO, T. Q.; HSU, A. Y.; JONASSEN, T.; LEE, P. T.; E CLARKE, C. F. A defect in coenzyme $\mathrm{Q}$ biosynthesis is responsible for the respiratory deficiency in Saccharomyces cerevisiae abcl mutants. J. Biol. Chem., v. 276, p. 18161-18168, 2001.

DO, T. Q.; SCHULTZ, J. R.; CLARKE, C. F. Enhanced sensitivity of ubiquinonedeficient mutants of Saccharomyces cerevisiae to products of autoxidized polyunsaturated fatty acids. Proc. Natl. Acad. Sci., v. 93, p. 7534-7539, 1996.

DRÖSE, S.; BRANDT, U. The mechanism of mitochondrial superoxide production by the cytochrome $b c 1$ complex. J. Biol. Chem., v. 283, p. 21649-21654, 2008.

DUCHEN, M.R. Mitochondria in health and disease: perspectives on a new mitochondrial biology. Mol. Aspects Med., v. 25, p. 365-451, 2004.

DUNCAN, A. J.; BITNER-GLINDZICZ, M.; MEUNIER, B.; COSTELLO, H.; HARGREAVES, P.; LÓPEZ, L. C.; HIRANO, M.; QUINZII, C. M.; SADOWSKI, M. I.; HARDY, J.; SINGLETON, A.; CLAYTON, P. T.; RAHMAN, S. A nonsense mutation in COQ9 causes autosomal-recessive neonatal-onset primary coenzyme Q10 deficiency: a potentially treatable form of mitochondrial disease. Am. J. Hum. Genet., v. 84 , n. 5, p. 558-566, 2009.

ECHTAY, K. S.; WINKLER, E.; KLINGENBERG, M. Coenzyme Q is an obligatory cofactor for uncoupling protein function. Nature, v. 408, p. 609-613, 2000.

ECHTAY, K. S.; WINKKER, E.; FRISCHMUTH, K.; KLINGENBERG, M. Uncoupling proteins 2 and 3 are highly active $\mathrm{H}+$ transporters and highly nucleotide sensitive when activated by coenzyme Q (ubiquinona), Proc. Natl. Acad. Sci. U.S.A., v. 98, p. 1416-1421, 2001.

ELAS, M.; BIELANSKA, J.; PUSTELNY, K.; PLONKA, P. M.; DRELICHARZ, L.; SKORKA, T.; TYRANKIEWICZ, U.; WOZNIAK, M.; HEINZE-PALUCHOWSKA, S.; WALSKI, M.; WOJNAR, L.; FORTIN, D.; VENTURA-CLAPIER, R.; CHLOPICKI, S. Detection of mitochondrial dysfunction by EPR technique in mouse model of dilated cardiomyophaty. Free Radical Bio. Med., v. 45, p. 321-328, 2008.

EPHRUSSI, B.; HOTTINGUER, H.; TAVLITZKI, J. Action de L'acriflavine sur les levures. II. - Étude génétique du mutant "petite colonie". Ann. Inst. Pasteur, v. 76, p. $1-24,1949$.

FARRELLY, F.; BUTOW, R. A. Rearranged mitochondrial genes in the yeast nuclear genome. Nature, v. 301, p. 296-301, 1983.

FAYE, G.; KUJAWA, C.; FUKUHARA, H. Physical and genetic organization of petite and grande yeast mitochondrial DNA. IV. In vivo transcription products of 
mitochondrial DNA and localization of $23 \mathrm{~S}$ ribosomal RNA in petite mutants of Saccharomyces cerevisiae. J. Mol. Biol., v. 88, n. 1, p. 185-203, 1974.

FELDMANN, H. Yeast: Molecular and Cell Biology. Weinheim: Wiley-VCH Verlag GmbH \& Co. KGaA, 2010.

FESTENSTEIN, G. N.; HEATON, F. W.; LOWE, J. S.; MORTON, R. A. A constituent of the Unsaponifiable Portion of Animal Tissue Lipids ( $\lambda_{\max } .272 \mathrm{m \mu}$.). Biochem. J., v. 59, p. 558-566, 1955.

FONTAINE, E., ICHAS, F.; BERNARDI, P. A ubiquinona-binding site regulates the mitochondrial permeability transition pore. J. Biol. Chem., v. 273, p. 25734-25740, 1998.

FORQUER, I.; COVIAN, R.; BOWMAN, M.K.; TRUMPOWER, B.L.; KRAMER, D. Similar transition states mediate the Q-cycle and superoxide production by the cytochrome $b c_{1}$ complex. J. Biol. Chem., v. 281, p. 38459-38465, 2006.

FOURY, F.; KUCEJ, M. Yeast mitochondrial biogenesis: a model system for humans? Curr. Opin. Chem. Biol., v. 6, p. 106-111, 2001.

FOURY, F.; CAZZALINI, O. Deletion of the yeast homologue of the human gene associated with Friedreich's ataxia elicits iron accumulation in mitochondria. FEBS Lett., v. 411, p. 373-377, 1997.

FOURY, F.; ROGANTI, T.; LECRENIER, N.; PURNELLE, B. The complete sequence of the mitochondrial genome of Saccharomyces cerevisiae. FEBS Lett., v. 440, p. 325$331,1998$.

FRIDOVICH, I. Superoxide radical and superoxide dismutase. Ann. Rev. Biochem., v. 64, p. 97-112, 1995.

GALKIN, A.; BRANDT, U. Superoxide Radical Formation by Pure Complex I (NADH:Ubiquinone Oxidoreductase) from Yarrowia lipolytica. J. Biol. Chem., v. 280, n. 34, p. 30129-30135, 2005.

GALPERN, W. R.; CUDKOWICZ, M. E. Coenzyme Q treatment of neurodegenerative diseases of aging. Mitochondrion, v. 7S, p. S146-153, 2007.

GARTLER, G.; STADLER, D. Herschel L. Roman (1914-1989). Genetics, v. 126, p. $1-3,1990$.

GERSHON, H.; GERSHON, D. The budding yeast, Saccharomyces cerevisiae, as a model for aging research: a critical review. Mech. Ageing Dev., v. 120, p. 1-22, 2000.

GIBSON, B. W. The human mitochondrial proteome: oxidative stress, protein modifications and oxidative phosphorylation. Int. J. Biochem. Cell B., v. 37, p. 927 934, 2005.

GILCA, M.; STOIAN, I.; ATANASIU, V.; VIRGOLICI, B. The oxidative hypothesis of senescence. J. Postgrad. Med., v. 53, n. 3, p. 207-213, 2007. 
GILLE, L.; NOHL, H. The existence of a lysosomal redox chain and the role of ubiquinona. Arch. Biochem. Biophys., v. 375, p. 347-354, 2000.

GIN, P.; HSU, A. Y.; ROTHMAN, S. C.; JONASSEN, T.; LEE, P. T.; TZAGOLOFF, A.; CLARKE, C. F. The Saccharomyces cerevisiae COQ6 gene encodes a mitochondrial flavin-dependent monooxygenase required for coenzyme Q biosynthesis. J. Biol. Chem., v. 278, p. 25308-25316, 2003.

GIN, P.; CLARKE, C. F. Genetic Evidence for a Multi-subunit Complex in Coenzyme Q Biosynthesis in Yeast and the Role of the Coq1 Hexaprenyl Diphosphate Synthase. J. Biol. Chem., v. 280, n. 4, p. 2676-2681, 2005.

GIORGIO, S.; LINARES, E.; ISCHIROPOULOS, H.; VoN ZUBEN, F. J.; YAMADA, A.; AUGUSTO, O. In Vivo Formation of Electron Paramagnetic Resonance-Detectable Nitric Oxide and of Nitrotyrosine Is Not Impaired during Murine Leishmaniasis. Infect. Immun., v. 66, n. 2, p. 807-814, 1998.

GLERUM, D. M.; SHTANKO, A.; TZAGOLOFF, A. Characterization of COX17, a yeast gene involved in copper metabolism and assembly of cytochrome oxidase. J. Biol. Chem., v. 271, n. 24, p. 14504-14509, 1996.

GOFFEAU, A.; BARRELL, B. G.; BUSSEY, H.; DAVIS, R. W.; DUJON, B.; FELDMANN, H.; GALIBERT, F.; HOHEISEL, J. D.; JACQ, C.; JOHNSTON, M.; LOUIS, E. J.; MEWES, H. W.; MURAKAMI, Y.; PHILIPPSEN, P.; TETTELIN, H.; OLIVER, S. G. Life with 6000 genes. Science, v. 274, n. 5287, p. 563-567, 1996.

GOEWERT, R. R. Studies on the Biosynthesis of Ubiquinone. St. Louis, MO: Saint Louis University, 1980.

GOGVADZE, V.; ORRENIUS, S.; ZHIVOTOVSKY, B. Mitochondria as targets for chemotherapy. Apoptosis, v. 14, n. 4, p. 624-640, 2009.

GOLIK, P.; BONNEFOY, N.; SZCZEPANEK, T.; SAINT-GEORGES, Y.; LAZOWSKA, J. Proc. Natl. Acad. Sci. U.S.A., v. 100, n.15, p. 8844-8849, 2003.

GRANDIER-VAZEILLE, X.; BATHANY, K.; CHAIGNEPAIN, S.; CAMOUGRAND, N.; MANON, S.; SCHMITTER, J.M. Biochemistry, v. 40, p. 97589769, 2001.

GRANT, C. M. Role of the glutathione/glutaredoxin and thioredoxin systems in yeast growth and response to stress conditions. Mol. Microbiol., v. 39, n. 3, p. 533-541, 2001.

GREEN, D. E.; HATEFI, Y. The Mitochondrial and Biochemical Machines. Science, v. 3445, n. 133, p. 13-19, 1961.

GRUNLER, J.; ERICSSON, J.; DALLNER, G. Branch-point reactions in the biosynthesis of cholesterol, dolichol, ubiquinona and prenylated proteins. Biochim. Biophys. Acta., v. 1212, p. 259-277, 1994. 
HANAHAM, D. Studies on transformation of E. coli with plasmids. J. Mol. Biol., v. 166, p. 157-163, 1983.

HARMAN, D. Aging: a theory based on free radical and radiation chemistry. J. Gerontol., v. 11, p. 298-300, 1956.

HENSLEY, K.; FLOYD, R. A. Reactive oxygen species and protein oxidation in aging: A look back, a look ahead. Arch. Biochem. Biophys., v. 397, p. 377-383, 2002.

HODGES, P. E.; MCKEE, A. H. Z.; DAVIS, B. P.; PASYNE, W. E. B.; GARRELS, J. L. Yeast Protein Database (YPD): a model for the organization and presentation of genome-wide functional data. Nucleic Acids Res., v. 27, p. 69-73, 1999.

HSIEH, E. J.; GIN, P.; GULMEZIAN, M.; TRAN, U. C.; SAIKI, R.; MARBOIS, B. N.; CLARKE, C. F. Saccharomyces cerevisiae Coq9 polypeptide is a subunit of the mitochondrial coenzyme Q biosynthetic complex. Arch. Biochem. Biophys., v. 463, p. 19-26, 2007.

HSU, A. Y.; DO, T. Q.; LEE, P. T.; CLARKE, C. F. Genetic evidence for a multisubunit complex in the O-methyltransferase steps of coenzyme Q biosynthesis. Biochim. Biophys. Acta, v. 1484, p. 287-297, 2000.

INOUE, Y.; MATSUDA, T., SUGIYAMA, K., IZAWA, S. AND KIMURA, A. Genetic analysis of glutathione peroxidase in oxidative stress response of Saccharomyces cerevisiae. J. Biol. Chem., v. 274, p. 27002-27009, 1999.

JAMES, A. M.; COCHEMÉ, H. M.; SMITH, R. A. J.; MURPHY, M. P. Interactions of Mitochondria-targed and Untarged Ubiquinones with the Mitochondrial Respiratory Chain and Reactive Oxygen Species. J. Biol. Chem., v. 280, n. 22, p. 21295-21312, 2005.

JAMIESON, D. J. Oxidative stress responses of the yeast Saccharomyces cerevisiae. Yeast, v. 14, p. 1511-1527, 1998.

JAZWINSKI, S. M. Yeast longevity and aging - the mitochondrial connection. Mech. Ageing Dev., v. 126, p. 243-248, 2005.

JOHNSON, A.; GIN, P.; MARBOIS, B. N.; HSIEH, E. J.; WU, M.; BARROS, M. H.; CLARKE, C. F.; TZAGOLOFF, A. COQ9, a new gene required for the biosynthesis of coenzyme Q in Saccharomyces cerevisiae. A. S. B. M. B., v. 36, p. 31397-31404, 2005.

JOHNSTON, M.; DAVIS, R. W. Sequences that regulate the divergent GAL1-GAL10 prometer in Saccharomyces cerevisiae. Mol. Cell. Biol., v. 4, p. 1440-1448, 1984.

KISHI, T.; MORRÉ, D. M.; MORRÉ, D. J. The plasma membrane NADH oxidase of HeLa cells has hydroquinone oxidase octivity. Biochim. Biophys. Acta, v. 1412, p. 6677, 1999. 
KOUTNIKOVA, H.; CAMPUZANO, V.; FOURY, F.; DOLLE, P.; CAZZALINI, O.; KOENIG, M. Studies of human, mouse and yeast homologues indicate a mitochondrial function for frataxin. Nat. Genet., v. 16, p. 345-351, 1997.

KOWALTOWSKI, A. J.; COSSO, R. G.; CAMPOS, C. B.; FISKUM, G. Effect of Bcl2 Overexpression on Mitochondrial Structure and Function. J. Biol. Chem., v. 277, n. 45, p. 42802-42807, 2002.

KRUFT, V.; EUBEL, H.; JÄNSCH, L.; WERHAHN, W.; BRAUN, H. P. Proteomic Approach to Identify Novel Mitochondrial Proteins in Arabidospsis. Plant Physiol., v. 127, p. 1694-1710, 2001.

KUDIN, A. P.; BIMPOG-BUTA, N. Y. B.; VIELHABER, S.; ELGER, C. E.; KUNZ, W. S. Characterization of Superoxide-producing Sites in Isolated Brain Mitochondria. J. Biol. Chem., p. 279, v. 6, p. 4127-4135, 2004.

KUSSMAUL, L.; HIRST, J. The mechanism of superoxide production by NADH:ubiquinone oxidoreductase (complex I) from bovine heart mitochondria. Proc. Natl. Acad. Sci. U.S.A., v. 103, n. 20, p. 7607-7612, 2006.

LAGIER-TOURENNE, C.; TAZIR, M.; LÓPEZ, L.C.; QUINZII, C.M.; ASSOUM, M.; DROUOT, N.; BUSSO, C.; MAKRI, S.; ALI-PACHA, L.; BENHASSINE, T.; ANHEIM, M.; LYNCH, D.R.; THIBAULT, C.; PLEWNIAK, F.; BIANCHETTI, L.; TRANCHANT, C.; POCH, O.; DIMAURO, S.; MANDEL, J.L.; BARROS, M.H.; HIRANO, M.; KOENIG, M. ADCK3, an ancestral kinase, is mutated in a form of recessive ataxia associated with coenzyme Q10 deficiency. Am. J. Hum. Genet., v. 82, n. 3, p. $661-672,2008$.

LENAZ, G.; FATO, R.; FORMIGGINI, G.; GENOVA, M. L. The role of Coenzyme Q in mitochondrial electron transport. Mitochondrion, 7S, p. S8-S33, 2007.

LERMAN-SAGIE, T.; RUSTIN, P.; LEV, D.; YANOOV, M.; LESHINSKY-SILVER, E.; SAGIE, A.; BEN-GAL, T.; MUNNICH, A. Dramatic improvement in mitochondrial cardiomyopathy following treatment with idebenone. J. Inherit. Metab. Dis., v. 24, p. 28-34, 2001.

LEUENBERGER, D.; BALLY, N. A.; SCHATZ, G.; KOEHLER, C. M. Different import pathways through the mitochondrial intermembrane space for inner membrane proteins. EMBO J., v. 18, p. 4816-4822, 1999.

LIOCHEV, S. I.; FRIDOVICH, I. Lucigenin as mediator of superoxide production: revisited. Free Radical Bio. Med., v. 25, p. 926-928, 1998.

LONGO, V. D.; LEE-LOUNG, L.; VALENTINE, J. S.; GRALLA, E. B. Mitochondrial Superoxide Decreases Yeast Survival in Stationary Phase. Arch. Biochem. Biophys., v. 365, n. 1, p. 131-142, 1999.

LÓPEZ-LLUCH， G.; RODRÍGUEZ-AGUILERA， J. C.; OCAÑA-SANTOS，C.; NAVAS, P. Is coenzyme Q a key factor in aging? Mech. Ageing Dev., v. 131, p. 225235, 2010. 
LOWRY, O. H.; ROSEBROUGH, N. J.; FARR, A. L.; RANDALL, R. J. Protein measurement with the Folin phenol reagent. J. Biol. Chem., v. 193, p. 265-275, 1951.

MAGNANI, T.; SORIANI, F. M.; MARTINS, V. P.; NASCIMENTO, A. M.; TUDELLA, V. G.; CURTI, C.; UYEMURA, S. A. Cloning and functional expression of the mitochondrial alternative oxidase of Aspergillus fumigatus and its induction by oxidative stress. FEMS Microbiol. Lett., v. 271, p. 230-238, 2007.

MARBOIS, B. N.; CLARKE, C. F. The COQ7 gene encodes a protein in Saccharomyces cerevisiae necessary for ubiquinone biosynthesis. J. Biol. Chem., v. 271, p. 2995-3004, 1996.

MARBOIS, B.; GIN, P.; FAULL, K, F.; POON, W. W.; LEE, P. T.; STRAHAN, J. Coq3 and Coq4 Define a Polypepetide Complex in Yeast Mitochondria for the Biosynthesis of Coenzyme Q. J. Biol. Chem., v. 280, n. 21, p. 20231-20238, 2005.

MARGULIS, L. Origin of eukaryotic cells. New Haven, CT: Yale University Press, 1970.

MCKENZIE, M.; LIOLITSA, D.; HANNA, M.G. Mitochondrial disease: mutations and mechanisms. Neurochem Res., v. 29, p. 589-600, 2004.

MEGANATHAM, R. Ubiquinone biosynthesis in microorganisms. FEMS Microbiol. Lett., v. 203, p. 131-139, 2001.

MEISTER, A.; ANDERSON, M. E. Glutathione. Ann. Rev. Biochem., v. 52, p. 711$760,1983$.

MELLORS, A.; TAPPEL, A. L. The inhibition of mitochondrial peroxidation by ubiquinone and ubiquinol. J. Biol. Chem., v. 241, p. 4353-4356, 1966.

MELOV, S.; SHOFFNER, J. M.; KAUFMAN, A.; WALLACE, D. C. Marked increase in the number and variety of mitochondrial DNA rearrangements in aging human skeletal muscle. Nucleic Acids Res., v. 23, p. 4122-4126. Published erratum appears in Nucleic Acids Res., v. 23, n. 23, p. 4938, 1995.

MITCHELL, P. The protonmotive Q cycle: a general formulation. FEBS Lett., v. 59, n. 2, p. 137-139, 1975.

MONTEIRO, G.; KOWALTOWSKI, A. J.; BARROS, M. H.; NETTO, L. E. S. Glutathione and thioredoxin peroxidases mediate susceptibility of yeast mitochondria to Ca2+ - induced damage. Arch. Biochem. Biophys., v. 425, p. 14-24, 2004.

NOBREGA, M. P.; NOBREGA, F. G.; TZAGOLOFF, A. COX10 codes for a protein homologous to the ORF1 product of Paracoccus denitrificans and is required for the synthesis of yeast cytochrome oxidase. J. Biol. Chem., v. 265, p. 14220-14226, 1990. 
NOBREGA, F. G.; NOBREGA, M. P.; TZAGOLOFF, A. BCS1, a novel gene required for the expression of functional Rieske iron-sulfur protein in Saccharomyces cerevisiae. EMBO J., v. 11, p. 3821-3829, 1992.

OHLMEIER, S.; KASTANIOTIS, A. J.; HILTUNEN, J. K.; BERGMANN, U. The yeast mitochondrial proteome, a study of fermentative and respiratory growth. J. Biol. Chem., v. 279, p. 3956-3979, 2004.

PADILLA, S.; JONASSEN, T.; JIMENEZ-HIDALGO, M. A.; FERNANDEZAYALA, D. J.; JOPEZ-LLUCH, G.; MARBOIS, B.; NAVAS, P.; CLARKE, C. F.; SANTOS-OCAÑA, C. Demethoxy-Q, an intermediate of coenzyme Q biosynthesis, fails to support respiration in Saccharomyces cerevisiae and lacks antioxidant activity. J. Biol. Chem., v. 279, p. 25995-26004, 2004.

PALTAUF, F.; KOHLWEIN, S. D.; HENRY, S. A. Regulation and compartimentalization of lipid synthesis in yeast. In: JONES, E. W.; PRINGLE, J. R.; $\mathrm{BROACH}$, J. R. (Ed.). The Molecular and cellular biology of the yeast Saccharomyces cerevisiae. New York: Cold Spring Harbor, 1992.

PONTIG, C. P.; ARAVIND, L. START: a lipid-binding domain in StAR, HD-ZIP and signalling proteins. Trends Biochem. Sci., v. 24, p. 130-132, 1999.

POON, W. W.; DO, T. Q.; MARBOIS, B. N.; CLARKE, C. F. Sensitivity to Treatment with Polyunsaturated Fatty Acids is a General Characteristic of the Ubiquinonedeficient Yeast coq Mutants. Molec. Aspects Med., v. 18, p. 121-127, 1997.

POON, W. W.; BARKOVICH, R. J.; HSU, A.Y.; FRANKEL, A.; LEE, P. T.; SHEPHERD, J. N.; MYLES, D. C.; CLARKE, C. F. Yeast and rat Coq3 and Escherichia coli UbiG polypeptides catalyze both O-methyltransferase steps in coenzyme Q biosynthesis. J. Biol. Chem., v. 274, p. 21665-21672, 1999.

PORTER, N. A. Mechanisms for the Autoxidation of Polyunsaturated Lipids. Acc. Chem. Res., v. 19, p. 262-268, 1986.

POU, S.; HASSET, D. J.; BRITIGAN, B. E.; COHEN, M. S.; ROSEN, G. M. Problems associated with spin trapping oxygen-centered free radicals in biological systems. Anal. Biochem., v. 177, p. 1-6, 1989.

RABILLOUD, T.; HELLER, M.; RIGOBELLO, M. P.; BINDOLI, A.; AEBERSOLD, R.; LUNARDI, J. The mitochondrial antioxidant defence system and its response to oxidative stress. Proteomics, v. 1, p. 1105-1110, 2001.

RABILLOUD, T.; KIEFFER, S.; PROCACCIO, V.; LOUWAGIE, M.; COURCHESNE, P. L.; PATTERSON, S. D.; MARTINEZ, P.; GARIN, J.; LUNARDI, J. Two-dimensional electrophoresis of human placental mitochondria and protein identification by mass spectrometry: toward a human mitochondrial proteome. Electrophoresis, v.19, p. 1006-1014, 1998.

RAHA, S.; ROBINSON, B. Mitochondria, oxygen free radicals, disease and ageing. Trends Biochem. Sci., v. 25, p. 502-508, 2000. 
REBRIN, I.; SOHAL, R. S. Pro-oxidant shift in glutathione redox state aging. Adv. Drug Deliver Rev., v.60, p. 1545-1552, 2008.

RICCHETTI, M.; FAIRHEAD, C.; DUJON, B. Mitochondrial DNA repairs doublestrand breaks in yeast chromosomes. Nature, v. 402, p. 96-100, 1999.

ROSE, M. D.; WINSTON, F. D.; HIETER, P. Methods in Yeast Genetics: A Laboratory Course Manual. New York: Cold Spring Harbor Laboratory Press, 1990.

ROTHBAUER, U.; HOFMANN, S.; MUHLENBEIN, N.; PASCHEN, S. A.; GERBITZ, K. D.; NEUPERT, W.; BRUNNER, M.; BAUER, M. F. Role of the DDP1hTim13 complex in import of human Tim23 into the inner membrane of mitochondria. J. Biol. Chem., v. 276, p. 37327-37334, 2001.

ROTHSTEIN, R. J. One step gene disruption in yeast. Methods Enzymol., v. 101, p. 202-211, 1983.

RUSTIN, P.; JACOBS, H. T. Respiratory chain alternative enzymes as tools to better understand and counteract respiratory chain deficiencies in human cells and animals. Physiol. Plant., v. 137, p. 362-370, 2009.

RUZICKA, F.; BEINERT, H.; SCHEPLER, K. L.; DUNHAM, W. R.; SANDS, R. Interaction of ubisemiquinone with a paramagnetic component in heart tissue. Proc. Natl. Acad. Sci. U. S. A., v. 72, p. 2886-2890, 1975.

SAMBROOK, J.; FRITSCH, E. F.; MANIATIS. T. Molecular Cloning. A laboratory manual. New York: Cold Spring Harbor, Cold Spring Harbor Laboratory Press, 1989.

SARASTE, M. Oxidative phosphorylation at the fin de siècle. Science, v. 283, p. 14881492, 1999.

SCHAEFER, A. M.; McFARLAND, R.; BLAKELY, E. L.; HE, L.; WHITTAKER, R. G.; TAYLOR, R. W.; TURNBULL, D. M.; CHINNERY, P. F.; Prevalence of mitochondrial DNA disease in adults. Ann. Neurol., v. 63, p. 35-39, 2007.

SCHAEFER, A. M.; TAYLOR, R. W.; TURNBULL, D. M.; CHINNERY, P. F. The epidemiology of mitochondrial disorders - Past, present and future. Biochim. Biophys. Acta, v. 1659, n. 2, p. 115-120, 2004.

SCHATZ, G.; HASLBRUNNER, E.; TUPPY, H. Deoxyribonucleic acid associated with yeast mitochondria. Biochem. Biophys. Res. Commun., v. 15, p. 127-132, 1964.

SCHIESTL, R. H.; GIETZ, R. D. High efficiency transformation of intact cells using single stranded nucleic acids as a carrier. Curr. Genet., v. 16, p. 339-346, 1989.

SEDDIKI, N.; MEUNIER, B.; LEMESLE-MEUNIER, D.; BRASSEUR, G. Is Cytochrome $b$ Glutamic Acid 272 a Quinol Binding Residue in the $b c 1$ Complex of Saccharomyces cerevisiae? Biochemistry, v. 47, p. 2357-2368, 2008. 
SEDENSKY, M. M.; MORGAN, P. G. Mitochondrial respiration and reactive oxygen species in mitochondrial aging mutants. Exp. Gerontol., v. 41, p. 237-245, 2006.

SHEN, Y.; GOLDSMITH-FISCHMAN, S.; ATREYA, H.S.; ACTON, T.; MA, L.; XIAO, R.; HONIG, B.; MANTELIONE, G. T.; SZYPERSKI, T. NMR structure of the $18 \mathrm{kDa}$ protein CC1736 from Caulobacter crescentus identifies a member of the START domain superfamily and suggests residues mediating substrate specifity. Proteins, v. 58, p. 747-750, 2005.

SIES, H.; MOSS, K. M. A role of mitochondrial glutathione peroxidase in modulating mitochondrial oxidations in liver. Eur. J. Biochem., v. 84, p. 377-382, 1978.

SLUSE, F. E.; JARMUSZKIEWICZ, W. Alternative oxidase in the branched mitochondrial respiratory network: an overview on structure, function, regulation, and role. Braz. J. Med. Biol. Res., v. 31, p. 733-747, 1998.

SOHAL, R. S.; MOCKETT, R. J.; ORR, W. C. Mechanisms of aging: an appraisal of the oxidative stress hypothesis. Free Radical Bio. Med., v. 33, p. 575-586, 2002.

SOHAL, R. S.; FORSTER, M. J. Coenzyme Q, oxidative stress and aging. Mitochondrion, v. 7S, p. S103-S111, 2007.

ST-PIERRE, J.; BUCKINGHAM, J.; ROEBUCK, S. J.; BRAND, M. D. Topology of superoxide production from different sites in the mitochondrial electron transport chain. J. Biol. Chem., v. 277, p. 44784-44790, 2002.

STADTMAN, E. R. Oxidation of free amino acids and amino acid residues in proteins by radiolysis and by metal-catalyzed reactions. Annu. Rev. Biochem., v. 62, p. 797821, 1993.

STADTMAN, E. R. Protein Oxidation in Aging and Age-Related Diseases. Ann. N. Y. Acad. Sci., v. 276, p. 1-37, 2001.

STARKOV, A. A.; FISKUM, G. Myxothiazol induces $\mathrm{H}_{2} \mathrm{O}_{2}$ production from mitochondrial respiratory chain. Biochem. Biophys. Res. Commun., v. 281, p. 645650, 2001.

STEINMETZ, L. M.; SCHARFE, C.; DEUTSCHBAUER, A, M.; MOKRANJAC, D.; HERMAN, Z. S.; JONES, T.; CHU, A. M.; GIAEVER, G.; PROKISCH, H.; OEFNER, P. J.; DAVIS, R. W. Systematic screen for human disease genes in yeast. Nat. Genet., v. 31, p. 400-404, 2002.

STEPHEN, A. G.; TRAUSCH-AZAR, J. S.; HANDLEY-GEARHART, P. M.; CIECHANOVER, A.; SCHWARTZ, A. L. Identification of a Region within the Ubiquitin-activating Enzyme Required for Nuclear Targeting and Phosphorylation. J. Biol. Chem., v. 272, n. 16, p. 10895-10903, 1997.

STURTZ, L. A.; DIEKERT, K.; JENSEN, L. T.; LILL R.; CULOTTA, V. C. A fraction of yeast $\mathrm{Cu}, \mathrm{Zn}$-superoxide dismutase and its metallochaperone, $\mathrm{CCS}$, localize 
to the intermembrane space of mitochondria. A physiological role for SOD1 in guarding against mitochondrial oxidative damage. F. Biol. Chem., v. 276, p. 38084-38089, 2001.

SUN, J.; TRUMPOWER, L. Superoxide anion generation by the cytochrome $b c 1$ complex. Arch. Biochem. Biophys., v. 419, p. 198-206, 2003.

SUPEKOVA, L.; SUPEK, F.; GREER, J. E.; SCHULTZ, P. G. A single mutation in the first transmembrane domain of yeast $C O X 2$ enables its allotropic expression. Proc. Natl. Acad. Sci. U.S.A., v. 107, n. 11, p. 5047-5052, 2010.

TAHARA, E. B.; BARROS, M. H.; OLIVEIRA, G. A.; NETTO, L. E. S.; KOWALTOWSKI, A. J. Dihydrolipoyl dehydrogenase as a source of reactive oxygen species inhibited by caloric restriction and involved in Saccharomyces cerevisiae aging. FASEB J., v. 21, p. 274-283, 2007.

TAKAYANAGI, R.; TAKESHIGE, K.; MINAKAMI, S. NADH- and NADPHdependent lipid peroxidation in bovine heart submitochondrial particles. Dependence on the rate of electron flow in the respiratory chain and an antioxidant role of ubiquinol. Biochem. J., v. 192, p. 853-860, 1980.

TARPEY, M. M.; FRIDOVICH, I. Methods of detection of vascular reactive species. Nitric oxide superoxide hydrogen peroxide and peroxynitrite. Circ. Res., v. 89, p. 224236, 2001.

TAUCHE, A.; KRAUSE-BUCHHOLZ, U.; RÖDEL, G. Ubiquinone biosynthesis in Saccharomyces cerevisiae: the molecular organization of O-methylase Coq 3 depends on Abc1p/Coq8p. FEMS Yeast Res., v. 8, p. 1263-1275, 2008.

THOMPSON, J. D.; HIGGINS, D. G.; GIBSON, T. J. CLUSTAL W: improving the sensitivity of progressive multiple sequence alignment through sequence weighting, position-specific gap penalties and weight matrix choice. Nucleic Acids Res., v. 22, p. 4673-468, 1994.

TRAN, Y. C.; CLARKE, C. F. Endogenous synthesis of coenzyme Q in eukaryotes. Mitochondrion, v. 7S, p. S62-S71, 2007.

TRAN, U. C.; MARBOIS, B.; GIN, P.; GULMEZIAN, M.; JONASSEN, T.; CLARKE, C. F. Complementation of Saccharomyces cerevisiae coq7 mutants by mitochondrial targeting of the Escherichia coli UbiF Polypeptide: two functions of yeast Coq7 polypepide in coenzyme Q biosynthesis. J. Biol. Chem., v. 281, p. 1640116409, 2006.

TROUNCE, I.; BYRNE, E.; MARZUKI, S. Decline in skeletal muscle mitochondrial respiratory chain function: possible factor in ageing. Lancet, v. 333, n. 8639, p. 637639, 1989.

TRUMPOWER, B. L. The Protonmotive Q Cycle. J. Biol. Chem., v. 265, n. 20, p. 11409-11412, 1990. 
TURRENS, J. F. Mitochondrial formation of reactive oxygen species. J. Physiol., v. 552, n. 2, p. 335-344, 2003.

TURUNEN, M.; OLSSON, J.; DALLNER, G. Metabolism and function of coenzyme Q. Biochim. Biophys. Acta, v. 1660, p. 171-199, 2004.

TZAGOLOFF, A. Mitochondria. New York: Plenum Press, 1982.

TZAGOLOFF, A.; AKAI, A.; NEEDLEMAN, R. B. Assembly of the mitochondrial membrane system. Characterization of nuclear mutants of Saccharomyces cerevisiae with defects in mitochondrial ATPase and respiratory enzymes. J. Biol. Chem., v. 250, p. 8228-8235, 1975.

TZAGOLOFF, A.; DIECKMANN, C. L. PET Genes of Saccharomyces cerevisiae. Microbiol. Rev., v. 54, n. 9, p. 211-225, 1990.

TZAGOLOFF, A.; MYERS, A. M. Genetics of mitochondrial biogenesis. Ann. Rev. Biochem., v. 55, p. 249-285, 1986.

TZAGOLOFF, A.; AKAI, A.; NEEDLEMAN, R. B. Assembly of the mitochondrial membrane system. Characterization of nuclear mutants of Saccharomyces cerevisiae with defects in mitochondrial ATPase and respiratory enzymes. J. Biol. Chem., v. 250, p. 8228-8235, 1975.

VAN LOON, D.; WESTERMAN, J.; AKEROYD, R.; WIRTZ, K.W. Identification of an essential lysine residue in the phosphatidylcholine-transfer protein from bovine liver by modification with phenylisothiocyanate. Eur. J. Biochem., v. 157, p. $347-350$, 1986.

VON JAGOW, G.; LJUNGDAHL, P. O.; GRAF, P.; OHNISHI, T.; TRUMPOWER, B. L. An inhibitor of mitochondrial respiration which binds to cytochrome $b$ and displaces quinone from the iron-sulfur protein of the cytochrome bc1 complex. J. Biol. Chem., v. 259, p. 6318-6326, 1984.

WALLACE, D. C. A mitochondrial Paradigm of Metabolic and Degenerative Diseases, Aging, and Cancer: A Dawn for Evolutionary Medicine. Annu. Rev. Genet., v. 39, p. 359-407, 2005.

WALTER, L.; NOGUEIRA, V.; LEVERSE, X.; HEITZ, M. P.; BERNARDI, P.; FONTAINE, E. Three classes of ubiquinone analogs regulate the mitochondrial permeability transition pore through a common site. J. Biol. Chem., v. 275, p. 2952129527, 2000.

WITTING, P. L.; PETTERSSON, K.; LETTERS, J.; STOCKER, R. Anti-atherogenic effect of coenzyme Q10 in apolipoprotein E gene knockout mice. Free Radic. Biol. Med., v. 29, p. 295-305, 2000.

WOLF. D. E.; HOFFMAN, C. H.; TRENNER, N. R.; ARISON, B. H.; SHUNK, C. H.; LINN, B. O.; MCPHERSON, J. F.; FOLKERS, K. Structure studies on the coenzyme Q group. J. Am. Chem. Soc., v. 80, p. 4750-4752, 1958. 
ZHANG, L.; YU, L.; YU, C. A. Generation of superoxide anion by succinatocytochrome c reductase from bovine heart mitochondria. J. Biol. Chem., v. 273, p. 33972-33976, 1998.

ZHANG, Y. I-TASSER server for protein 3D strutucre prediction. BMC Bioinformatics, v. 9, p. 40, 2008.

YU, B.P. Cellular defenses against damage from reactive oxygen species. Physiol. Rev., v. 74, p. 139-162, 1994. 